\title{
Impact of Retirement on Mental Health
}

\author{
Dr Veeramuthu and Dr B. Shanthi \\ Tamil Nadu Dr. M. G. R. Medical University, Chennai
}

\section{Introduction}

One of the most significant events in the life of the aging man is retirement. Even though retirement brings about some expected disruptions in the life of a person, it is obvious that some are more affected than others are (Atchley, 1976). Retirement is clearly listed as one of the stressful life events where a person feels discriminated from society and has to undergo numerous readjustments. It is then but natural to experience symptoms of anxiety, depression, frustration, diminished sense of worth, shattered self-esteem and morale. Studies done by Dhillon and Milbander (1992) showed that retired men were more tense, anxious and psychologically demoralized than working men.

As Cox (1984) states that on one hand, retirement is viewed as a well deserved right earned by long years of hard work in a particular occupation and on the other hand there is a tacit feeling that one is being forced out of a chosen career and the opportunity for gainful employment. These views are held mostly for mandatory retirement. The dictionary meaning of the term to retire is "to retreat, to recede, to withdraw from society, office, public or active life" and retirement as "an act of retiring". Since the term retirement implies withdrawal from society, active life, work and career, there are paradoxical views on it in the minds of people.

It is felt that chronological age is a poor indicator of the ability to determine between work and mandatory retirement.

Retirement is viewed as a period of crisis and adjustment where a number of problems confront the individual. Cox (1984) states that some of the problems are lowering of income, loss of status, loss of privilege, reorganization of daily activities, changing perception of self, social isolation and a sense of meaninglessness. However Streib and Schneider (1971) obtained contrary research findings. They found that although retirees experienced a sharp drop in income, they did not feel a decline in status of class.

There are various types of retirement such as normal retirement or superannuation, early retirement and voluntary retirement. In the Indian industrial sector, the word voluntary retirement received legislative recognition in 1953 when the definition of retirement was engrafted in the Industrial Disputes Act, 1947. In India the age of retirement is 58 - 60 years.

Voluntary Retirement Scheme (VRS) or "Golden handshake" has become one of the ways of dealing with redundant human resources in an organization. Thus VRS is a situation where the employee discontinues from job before stipulated age. People accept VRS because of an uncertain future, financial needs, ill health, and dissatisfaction with the jobs or allurement by management. Various studies done by Atchley (1976) and Indian studies by Gupte, Kumar et al (1994) show that majority faced repentance, unemployment because of lack of specialized skills, frustration, economic hardship and a bleak long term future.

In India where per capita income is low and unemployment levels are high, VRS further aggravates the situation by adding to the unemployed population. The people most severely affected are the semiskilled or unskilled workers of middle income group as they are the target population. This population faces more psychiatric morbidity than normal retired population because of the suddenness of the situation and more fruitful years of their life wasted in unemployment and inability to get jobs at the same salary level (Walker, 1985).

Simpson (1966) states that work is one of most important avenues for integrating the individual into the social system by giving him or her an identity, style of life and social participation pattern. Work places the individual and his family in the hierarchy of the social structure. Thus retirement is viewed as being forced out of a chosen career and gainful employment (Cox 1984). At this phase of life, various stressful life events and readjustments occur. People in general and retirees in particular are emotionally, socially and sometimes financially and physically dependent on others. At the twilight of life, individuals from all occupations face various stressors. These stressors can be dealt with in an astute manner by the retired and working populations greater than the age of 60 years due to the supportive family system in India.

But the resolutions of these stressors and the contentment of life that a working population achieves will be slightly higher because they are involved in productive tasks, are occupied and thus active, both physically and mentally. This makes them feel more independent, confident and capable of solving their personal and social problems.

As mentioned earlier, at the time of retirement, a person faces sudden changes in one's lifestyle. The changes are seen from the daily routine to active interests. Retirement also leads to change in the feeling of confidence and personal worth as they are cut off from participating in the most important interests and 
activities of society (Aldrich and Lipman, 1976). Therefore it was felt necessary to analyze self esteem and life satisfaction of the individuals in the present research.

It is believed that due to our philosophical attitudes and family structure, the aged in India are able to bear the losses in life without suffering from depression. Contrary to this common belief, various community surveys have revealed that depression is the most common psychiatric disorder in late life. Ramchandran and Palaniappan (1983) in a geropsychiatric community survey in Chennai found $24 \%$ of subjects aged 60 years and above suffering from depression. Retirement is taken as one of the stressful life events leading to psychiatric morbidity. This study further explores the extent of psychiatric morbidity (depression) between types of retirement and working population.

In gerontology, adjustment means a bad effect to internal as well as external equilibrium of the humans (Rosow, 1963). The retired population is more susceptible to adjustment problems as compared to working elderly populations, especially in the areas of health, home, self, emotional and social life (Bose, 1982). Therefore the need was felt to explore the level of adjustment in the various areas mentioned above. India being a developing country, the status of aged women has not been equal with the status of aged men in the familial, sociological and psychological spheres. Despite the increasing inroads in education and technology, the familial status doesn't seem to have undergone any radical changes (Jamuna, 1989). In the past few years, women have crossed the threshold of their homes and have started working. Studying gender differences in the aspects of adjustment, life satisfaction, depression and self-esteem was essential to the study.

\author{
Review of Literature \\ History and Evolution \\ Phases of Retirement \\ Epidemiology \\ Psychosocial Consequences of Retirement \\ Retirement and Social Relationships \\ Retirement and Leisure Participation \\ Retirement and Adjustment \\ Retirement and Gender Differences \\ Employment in Older Workers \\ Voluntary Retirement
}

\title{
History and Evolution
}

Retirement has steadily grown in importance in industrial societies. It has changed from a rare and novel social pattern to a practically universal social institution it can be viewed as a process, event, social role or a phase of life. Retirement is a creation of industrial society. In the pre-industrial era people did indeed stop working because of old age but there was no way that a person could earn the right to an income (pension) without doing a job or owning enough property to provide it.

In early societies, older people were supported only so long as they could perform some sort of productive function. For e.g. if the Eskimos grandmother could no longer chew the hide for boots she would be abandoned (Donahue, Orbach, 1960). The advent of an agricultural society brought two important developments - an economic surplus and the concept of property. Thus older people who had gained property rights could support themselves in old age because they had the power of ownership. Those who lived to become old tended to be from the upper economic strata in which financial power had traditionally been used to support the lower economic strata of population. But the laborer who did not have property rights and could no longer work had to fall back on the benevolence of their family and well-to-do members of society.

Industrialization brought many changes. Industrial form of production drastically increased available economic surplus. The main reasons for this increase in productivity were man's discovery of non-human energy to produce goods. As urbanization increased and fertility rates declined, with a decrease in mortality, a larger proportion of the population was in the older age group. Industrialization upset the system of older people retaining power. In industrial society people from all walks of life survived to become old. Industrialization decreased the power of older people by divorcing management from ownership and putting a cover premium on experience. Therefore the scientific revolution destroyed the role of elders as bridges to the dead generation. The rise of corporations and large-scale organizations for production eliminated the family with its patriarchal head as a typical unit of production. This paved the way for the argument that people should be relieved of their duties in old age because they were no longer capable of meeting minimum standards. Industrialization helped to dissociate the concept or work from the concept of life itself.

Craftsmanship was the ideal of work in the pre-industrial era. The craftsman was the master of a product and the process of creating it. Industrialization reduced the job for many people to a fragment of a 
process. For workers in corporations or government bureaucracies, jobs moved towards being an element of life instead of a craft around which ones life revolved (Mills, 1956).

For these reasons the stage was set for the development of retirement in a maturing industrial society. People were living long enough to contribute to the necessary work in an economy and still have several potentially productive years of life left.

The rationalization of labour, the decline of entrepreneurship and the rise of a secular city meant that it was neither always possible nor desirable for individuals to hold a job into old age. People, thus, began to accept without guilt the concept of retirement as an earned right. Also during the era of industrialization, concerns regarding human efficiency led to studies of the physical and mental decline caused by aging. Old age was increasingly depicted as a period of decline, weakness, inactivity and dependency rather than wisdom and fulfillment. Child labor laws and compulsory education led to the segregation of the young while mandatory retirement age contributed to the isolation of the elderly. This led to the creation and eventual acceptance of negative stereotypes of old ages. (Haravan, 1995)

In India, old age is recognized as a source of prestige and honor where elders are respected and given authority in family and household matters. The Ashram Theory of life in India presents a systematic approach to life in developmental forms, namely Brahmacharya, Garhastha, Vanaprastha and Sanyas - recognize withdrawal from society as an approach to old age. Japan, due to Buddhism has a similar pattern of respect for the aged. In Japan, the head of the family seeks retirement called 'Inkyo' (retirement from active service) which is comparable to Vanaprastha. Inkyo is a legal and social status. Due to industrialization and urbanization these old traditions have become perfunctory. At the start of the century, only a few people lived up to 65 yrs and hence they did not cause a social problem. Therefore, men died before they reached the age of retirement, when it did occur, it was limited to the higher income brackets. Today, the retired are faced with making major adjustments to a world based on principles alien to the traditional socialization (Nagar, 1989). Retirement has often been called $3^{\text {rd }}$ age in France. The drop in income creates a section of society well endowed with free time but with leisure interests more limited than any other age group. (Jeffery, 1991)

Retirement is a new phenomenon; in as much as in the second half of the $20^{\text {th }}$ century, for the first times almost everyone is going to spend a significant number of years living in retirement. It is inevitably associated with a number of types of losses - loss of finance, status, companionship and purposeful occupation. (Brocklehurst, Allen, 1987).

The process of growing old began in adulthood and its repercussions can be seen in biological, sociological and psychological markers. The point at which one can be said to be old is unclear. The cut off is normally the age of retirement, thus 65 years is arbitrarily designated as beginning of old age, or third age (Laslett, 1989).

In the United States of America, the Social Security Act of 1935 established 65 years as the age of retirement (A Report on the Nation and its Older People - US Dept. of Health, Education and Welfare, 1986). In terms of numbers, this was $15-20 \%$ of the population by the end of the century as compared to $5 \%$ at the beginning of century.

Freud himself was not interested in psychological developments and changes consequent upon the aging process although some of those influenced by his ideas were. Jung (1972) placed greater emphasis on the second half of life and significant changes in this period. Mid life was a turning point, which afforded the individual opportunities for new development. He laid much emphasis on introspection and symbolic and religious experiences in creating harmony within personality and between individuals and the outside world. Erik Erikson (1956) too, in "Integrity v/s Despair" has seen older people are trying to achieve integrity and wholeness of life and to fight the despair of inability to live again a life differently from the one he lived. Peck (1968) maintained that psychological growth in old age is characterized by three psychological tasks:

- Ego differentiation versus work role preoccupation: This focuses on the impact of vocational retirement and differences for many older people in securing a strong sense of identity and purpose in the absence of work. Personal work must be redefined so that a retired person can take satisfaction in activities and relationships beyond those of work.

- A sense of self worth derived from other activities is important for a vital interest in living.

- Body transcendence versus body preoccupation: This task refers to an increased incidence of ill health in later years and its impact on psychological well being. The worst outcome is a preoccupation with their bodies. There may be others who experience ill health but still enjoy life.

- Ego transcendence versus ego preoccupation: This is similar to Erikson's "Integrity versus Despair", which according to Peck means to live fully knowing that death is inevitable.

\section{Phases of Retirement}

There are six phases of retirement. (Atchley, 1976) 
1. Pre-retirement phase: is divided into 2 phases - remote and near.

In the remote phase few people dread retirement. The exceptions to this are those employers who expose their employees to formal programs focused on retirement planning during the remote phase. Developing leisure skills is another prerequisite of the retirement role. These skills should be learnt in the earlier phases of preretirement. Smooth adjustment to retirement is associated with financial security and personal adaptability.

Near phase begins when the individual becomes aware that he will have to take retirement role soon. Attitude generally becomes more negative during near retirement phase because the realities become clearer. Preretirement planning programs help to offset the negative stereotype concerning retirement. The topics range from - financial planning and use of leisure time.

2. Honeymoon phase: This is a euphoric period where an individual. Wallows in his newly found freedom of time and space.

3. Disenchantment phase: Once the honeymoon phase is over, life slows down and people may get depressed. People who have few alternatives, poor health, little money, or who were over-involved in their jobs are apt to experience deep and lengthy periods of depression. Disenchantment phase also results from failure of anticipatory socialization for retirement. Most people work their way through this phase, but some remain in this phase.

4. Reorientation Phase: This process involves using one's experience as a retired person to construct alternatives which are realistic. It means exploring new avenues. The outcome of the reorientation process in the retirement period is to develop a structure and routine in life which gives at least minimum satisfaction.

5. Stability phase: This refers to the routinization of criteria for dealing with change and not absence of change. Life in this phase is mostly predictable and satisfying. Some pass into this phase directly from the honeymoon phase, some reach it after painful assessment, while others may never reach it. It is the ultimate phase in terms of role-playing. In this phase, the retired person knows what is expected of him and what his capabilities and limitations are. Physical decline occurs here and changes his level of functioning but these can be incorporated into the routine without changing the criteria for making choices.

6. Termination Phase: When a person is invalid for major activities, he is transferred from the retirement role to a sick role. This transfer causes loss of independence and status and financial support, which are required for playing the retirement role. The increasing dependence forced by old age comes gradually and the retirement role is given up in this stage.

\section{Timing of phases}

There is no way to tie the phases of retirement to chronological age or to a period of time. These phases refer to a typical progression of processes Involved in approaching, playing and giving up the retirement role. Any an individual may not experience all the phases.

\section{Epidemiology \\ Growth of the Elderly: Global view}

The number of aged in the world population will be more than double, from 500 million in 1990 to over one billion by 2025. This increase will be more in developing countries. The number of people more than 60 years by the year 2025 will be over 800 million (WHO, 1982). Contributing to this momentum in population aging is the fact that over the last generation, life expectancy has risen by almost 10 years. For a child born in 1986 it is 74.9 years. (US senate special committee on aging, 1986)

\section{Growth of the Elderly: Indian view}

In 1911 there were 2.52 million Indians over the age of 60 years, comprising $1.4 \%$ of the total population. In the 1991 census there were 50 million people above the age of 60 years, thus comprising $6.21 \%$ of the population. In 2001, the elderly population has increased to $7.4 \%$ of the total population. This change is because of the change in life expectancy and mortality. 


\section{Growth of the Elderly in India}

\begin{tabular}{|l|c|c|c|c|c|c|c|c|c|c|}
\hline & \multicolumn{4}{|c|}{ Number (in Millions) } & \multicolumn{3}{c|}{ Percent of Elderly to the total population } \\
\cline { 2 - 13 } & 1961 & 1971 & 1981 & 1991 & 2001 & 1961 & 1971 & 1981 & 1991 & 2001 \\
\hline $60+$ & 25 & 33 & 43 & 57 & 77 & 5.6 & 6 & 6.49 & 6.76 & 7.5 \\
\hline $70+$ & 9 & 11 & 15 & 21 & 29 & 2 & 2.1 & 2.33 & 2.51 & 2.9 \\
\hline $80+$ & 2 & 3 & 4 & 6 & 8 & 0.6 & 0.6 & 0.62 & 0.76 & 0.8 \\
\hline $90+$ & 0.5 & 0.7 & 0.7 & 1 & n.a & 0.1 & 0.1 & 0.1 & 0.2 & n.a \\
\hline $100+$ & 0.01 & 0.01 & 0.01 & 0.01 & n.a & 0.02 & 0.02 & 0.02 & 0.02 & n.a \\
\hline
\end{tabular}

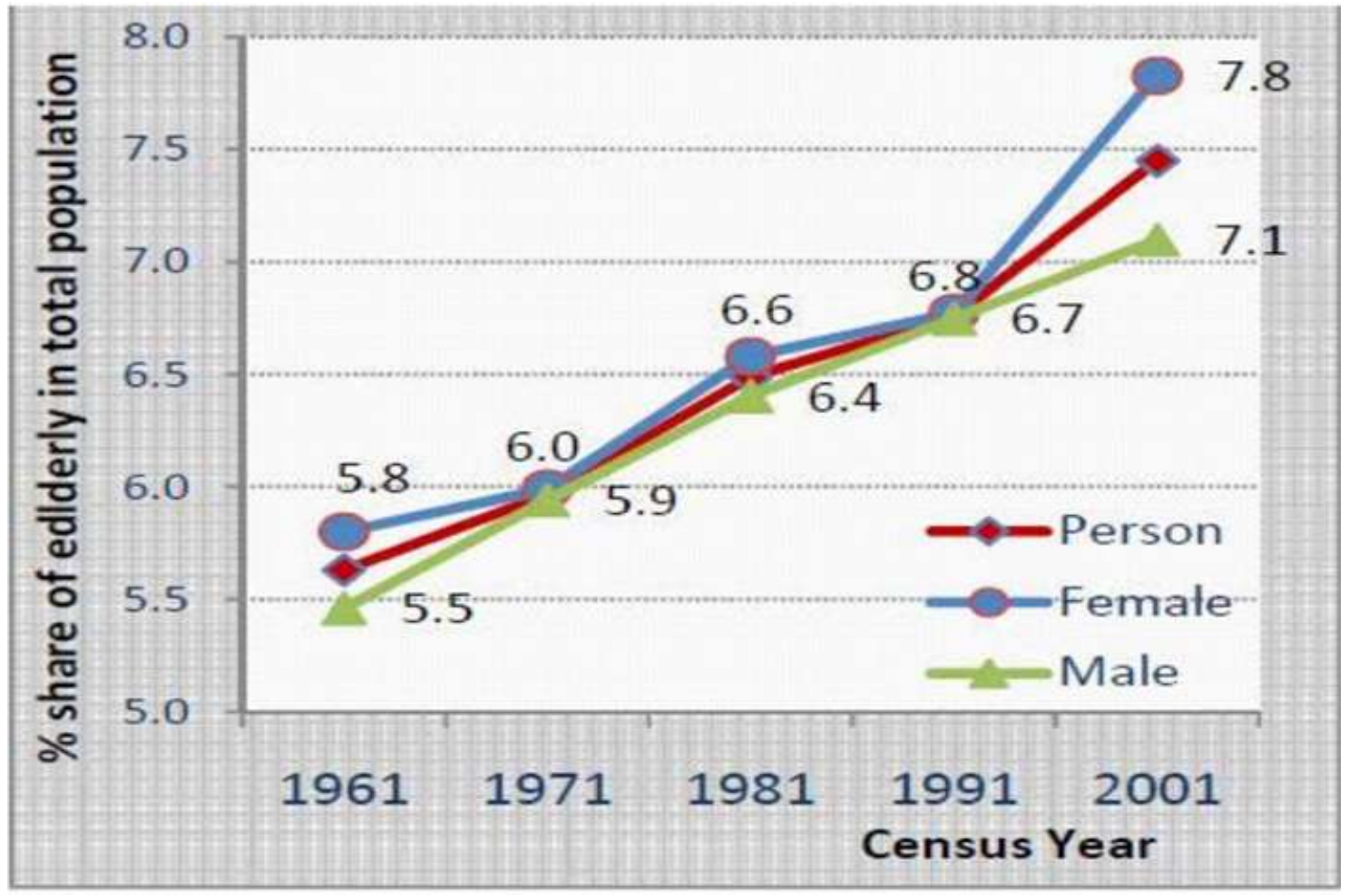

\section{Dependency Ratio:}

This compares the number of economically productive versus economically non-productive individuals. The aged dependency percentage is on the increase since the past few decades. In 1971 there were 32.59 million aged dependants but in 1991 there were over 50 million dependants. The dependency ration has now climbed to $13.1 \%$ in 2001 for India as a whole. For females and males the value of the ratio was $13.8 \%$ and $12.5 \%$ in 2001 . The burden of the aged dependants falls to a large extent on the productive population. (Dhillon, 1992)

Dependency Ratio of the Elderly

\begin{tabular}{|l|r|r|r|r|r|}
\hline Year & All & Male & Female & Rural & Urban \\
\hline 1961 & 10.9 & 10.9 & 10.9 & 11.4 & 8.7 \\
1971 & 11.5 & 11.4 & 11.6 & 12.2 & 8.9 \\
$1981^{*}$ & 12.0 & 11.8 & 12.2 & 13.0 & 9.2 \\
$1991^{* *}$ & 12.2 & 12.2 & 12.2 & 13.2 & 9.7 \\
$2001+$ & 13.1 & 12.5 & 13.8 & 14.1 & 10.8 \\
\hline
\end{tabular}




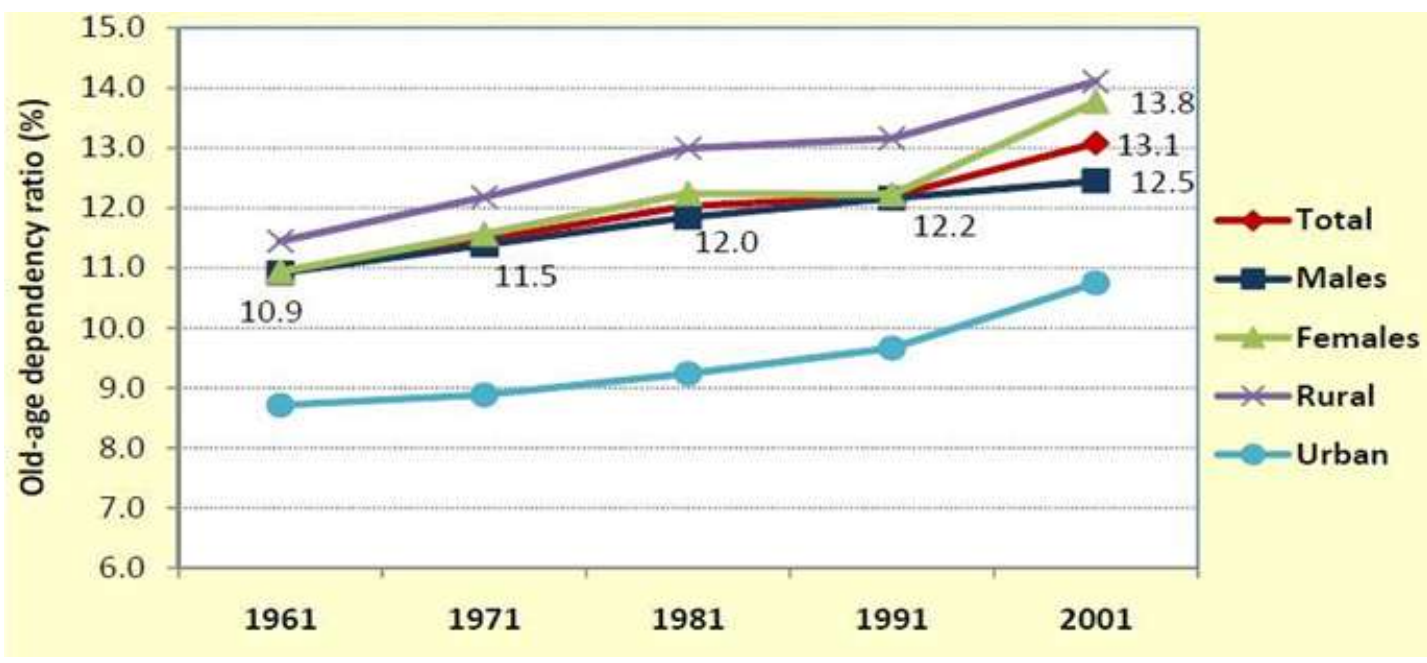

Population of the Elderly by Sex Ratio: The changes in the demographic structures of the societies during the last few decades, particularly in developing countries, have made the aged a socially more noticeable section of the population. (Bhatia, 1983). In almost all the developed countries elderly women outnumber elderly men after the age 65 years. In India too, life expectancy for women is nearly equal to that of men. In 1971 the population of men over 60 years of age was 14.6 million and that of women was 13.5 million. In 2001 the comparable figures were 36 million men and 35.3 million women respectively.

\section{Population of the Elderly by Sex Ratio}

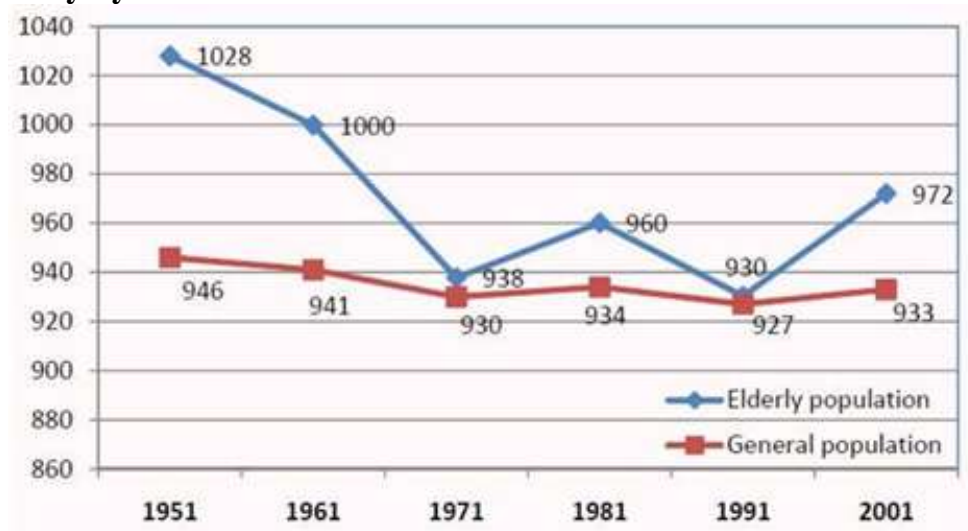

\begin{tabular}{|l|c|c|c|c|c|c|c|}
\hline \multirow{2}{*}{} & \multicolumn{6}{|c|}{ Sex Ratio of Elderly (males per 1000 females) } & \multicolumn{3}{c|}{ Growth of Elderly (Percent) } \\
\cline { 2 - 8 } & 1971 & 1981 & 1991 & 2001 & $1971-81$ & $1981-91$ & $1991-2001$ \\
\hline $60+$ & 1066 & 1042 & 1075 & 1028 & 2.78 & 2.72 & 3.04 \\
\hline $70+$ & 1030 & 1026 & 1084 & 991 & 3.13 & 3.08 & 3.32 \\
\hline $80+$ & 950 & 990 & 1090 & 1051 & 2.54 & 4.35 & 2.35 \\
\hline $90+$ & 897 & 892 & 1019 & n.a & 0.66 & 5.08 & n.a \\
\hline $100+$ & 798 & 844 & 896 & n.a & 0.19 & 0.44 & n.a \\
\hline
\end{tabular}

\section{Psychosocial Consequences of Retirement}

The impact of retirement is tremendous as it results in a loss of role, status, power and opportunities for interaction. As Miller (1965) states it also causes a "loss of occupational identity" with the result that the individual withdraws from society. Thus retirement can affect various dimensions in one's life. The personal and situational consequences are discussed below.

Personal Consequences

These can be discussed under the following headings: 


\section{Physical Health:}

Physical health plays a major role in every individual' $\mathrm{s}$ life. It is related to adjustment and well being (Palsane, 1970). Earlier work emphasized on negative aspects of retirement and physical health. However researchers like Makides and Cooper (1989) have described the positive effects. McGoldrick (1989) has concluded that as long as retirement is not on health grounds and there is adequate financial support, retirement has a beneficial impact on health. A number of variables need to be taken into account when considering the relationship between retirement and health status. The most significant ones are:

- Whether retirement is financially viable

- Extent to which an older person can adjust to the change in lifestyle (particularly increase in leisure time).

- Whether retirement was considered voluntary or involuntary.

- Extent to which an older person enjoys social support.

It is widely held that retirement has an adverse effect on health. The question arises whether people retire because they are sick or whether they are sick because they retire. Based on the data from a longitudinal study of before and after retirement, Streib and Schneider (1971) concluded that health decline is associated with age and not with retirement. In fact unskilled workers showed a slight improvement in health following retirement. On the other hand, Haynes et al (1978) monitored the mortality rates for two years in working groups $(>=65$ years) and early retirement groups. Although he found an increase in ill health in the latter, it probably reflected that ill health led to early retirement. However in the follow up study after 4 years, the rate was still higher in the retirement group. Salem (1976) has also found similar results and has associated the increase in morbidity and mortality with the disenchantment process (Atchley, 1976).

However Ellison (1968) contends that illness that follows retirement is a psychosomatic ploy used as justification for becoming dependent on children. The retired persons see retirement as robbing them of a place in society and adopting a sick role as a way of getting back into the system.

\section{Mental disorders}

Mental Health in the elderly is an area of serious concern because of the increasing prevalence of mental breakdown and suicides among the elderly (Sethi, 1982). Retirement often results in 'retirement shock' in some people. More often it is the prospect of retirement rather than retirement itself that causes greater conflict and contributes to an unsettled state of mind.

The pervading impression that he is 'old and needs rest' along with his diminished sense of worth and power, gives rise to emotional problems that shatter his self esteem, morale and self worth. Studies by Dhillon and Milbander (1992) found more anxiety, tension and apprehension in the retired as compared to working populations. Contrary to these studies, Lowenthal (1964) found that mental illness causes retirement rather than the other way around. However Lowenthal and Berkman (1967) found that association between retirement and mental health was mainly a function of poor health; low social activity and unsatisfactory living arrangements rather than retirement per se. Nadelson (1969) has also found no adverse effects of retirement on mental health.

However, opinion is divided regarding this issue. Cottrell and Atchley (1969) found depression was uncommon, but $10 \%$ of their sample showed a high degree of depression. Women showed more of depression as compared to men and particularly among teachers. Pitt (1990) has shown that retirement does contribute to psychological problems.

However good health, adequate means, absorbing interests and congenial company can give a successful retirement. Rao (1982) in a survey near Madurai found that depressive illness contributed to $67 \%$ of the total psychiatric morbidity of the aged. Other mental disturbances included anomie, loss of sense of meaning, frustration, anxiety and a feeling of uselessness (Edwards, 1983). Therefore retirement, health, relocation and widowhood are all stresses in old age that are hurdles, which if not surmounted, result in mental ill health.

\section{Life Satisfaction}

Morale and life satisfactions are two concepts used to identify a general construct for an overall emotional reaction to one's life. Simpson and Back (1969) found that morale is influenced as much or more by health, family situation and other factors besides retirement. Streib and Schneider (1971) found no significant changes in life satisfaction.

Financial condition is a strong predictor of life satisfaction prior to retirement and health is a strong predictor after retirement for life satisfaction. (Dhillon, 1992). According to Hamlin (1967) task oriented retired people had more positive life satisfaction than non-task oriented. Aldrich (1976) also found that working population had better satisfaction than retired population. 


\section{Situational Consequences:}

Situational consequences of retirement are related to Income, Change of Residence, Changing Family Structure and Marriage.

\section{Income}

Income loss is the item of life which retirees miss the most after retirement, especially if they have children plus dependants to support after their retirement and especially in case of compulsory retirement. (Bhatia, 1983). Income in retirement becomes half; feelings of economic deprivation also increase (Riley and Foner, 1965). Clark and Anderson (1967) found that reduced income had a significant impact on self-image especially for those of low socio-economic scale. For the average retired Indian, the main source of income is either his monthly pension or savings under the Employees' Provident Funds Act (1952). In India, Article 41 of the Constitution lays down, as one of the directives, that the state should make provisions for work, education and public assistance for the persons who are not employed, sick or aged. However as far as welfare of old peoples are concerned, India has not as yet developed any comprehensive old age security system.

The government has provided legislation for many schemes, however inflation has wiped out much of the purchasing power of money, thus making elderly dependent on the others for their needs (Malik, 1980).

Peterson (1972) studied the perceptions of retired concerning the adequacy of their income and found that majority considered it inadequate. Streib and Thomson (1957) have suggested that an individual's own feeling of economic deprivation or appraisal of adequacy of his own income is more meaningful than his objective income. Studies by Mishra (1989) have shown that if people engage in an occupational activity in old age they can remain in a better financial position.

The rights of a retired person includes the right to economic support without holding a job and without the stigma of being regarded as dependent on society as in the case of unemployed. The expectation is that the retired people are to be self dependent and not be a burden to the family or community. Although income without a job holding is a reward for retirement, denigration is a punishment for those retired people who become dependent.

\section{Change of residence}

It is seen that retirement has little impact on migration. Langford (1962) found reason for moving was to get a secure, suitable dwelling, which is more economical with better facilities. In the past few years, in foreign countries different types of specialized facilities have been developed to help meeting the housing needs of the elderly. These are called retirement communities, which are self-contained.

This is done to prevent problems in adjusting housing and social life. But studies by Yamashita et al (1993) have shown that people living like this have more prevalence of depression and lower life satisfaction than people in their own homes.

\section{Changing family structure}

After retirement the aged have to depend on their family members for various needs. Now with industrialisation, the joint family system is giving way to the nuclear family. This further leads to neglect. Bose (1982) reports that only $50 \%$ of aged enjoys the status of head of household. Hence good family relations are necessary for adjustment in old age. Widowhood and empty nest are two age-related factors that coincide with retirement. Percentage of women who face retirement as widows is nearly four times higher than for men. Thus absence of family support makes widowhood more difficult in adjusting to retirement. If widowhood and retirement coincide then the impact of retirement is perceived as more negative. Empty nest is not taken as a factor influencing retirement because empty nest is a phenomenon, which occurs for most parents long before retirement.

However, to the extent that the job is used as a vehicle for adjusting to empty nest, retirement brings not only the problems of adjusting to retirement but also demanding a new adjustment to empty nest. The same can be said if the job is used to compensate for widowhood. Menachery (1987) studied the overall position of the retired and found it to be above average, because of respect of aged in Indian families. However, a lowering was found in family relations following retirement. Other factors like family responsibility, cultural values, and socio-economic status decide the change in family relationships. Therefore retirement has no impact on family relations per se, but depends on intra family relationships.

\section{Marriage}

Family is a major institution for providing long lasting primary, social and emotional ties with others. Marital status plays an especially important role after retirement due to total dependence on family for the fulfillment of all the interpersonal needs. (Russell, 1979). Kerchhoff (1966) found that retirement could be expected to affect the relationships within couples. He found that retiring husbands look forward to retirement, 
experience satisfaction in retirement and are more involved in the retirement process as compared to the wives. This was due to the husbands' greater involvement in household task following retirement. Heyman and Jeffers (1968) found that the wives who regretted their retirement were those who were from a working class and whose husbands were in poor health and those who were unhappy before marriage. The change that occurs following retirement is also in the quality of role playing, especially in the family. In Western set ups, retired men take a more active role in the care of the household. Middle class wives welcome this trend, but working wives often do not. Generally retirement increased marital satisfaction (Rollins and Feldman, 1970).

\section{Retirement and Social Relationships}

Retirement frees people from the necessity to live close to their jobs. It increases the utilization of existing housing in out of way areas. Social participation involves interactions or contact with friends. Cottrell and Atchley (1969) reported no or minimal change in social life with retirement. Loether (1967) found major changes in interpersonal relationships as a result of retirement. For most men the most important interpersonal relationship, outside their family relation arises directly from their work situations. Satisfaction with ones work may result not only from the job but also due to the satisfying relation with fellow workers. Thus retirement means more than physical separation from colleagues. It means a change in social relationships. Hochschild (1973) said that the main problem of older people is isolation from family and work due to the decline in work, age stratification, and weakening of kinship ties. This sudden fall in social contacts following retirement may create social isolation. Russell (1979) thus gives the importance of interaction with friends, neighbors, relatives and members of social organizations.

In Indian studies like the one by Bhatia (1983), only $15 \%$ were found to be socially isolated. This may be because of the nature of Indian families and our social structure, which is a close knit one.

\section{Retirement and Leisure Participation}

Many aged people cannot cope with the amount of time on their hands and become victims of idleness, loneliness, boredom and frustration. This problem is more acute in India because of a lack of recreation for the normal population (Chowdhary, 1981). Lawton (1951) has pointed out that self expression is possible even in old age through various creative hobbies. Thus retired people should get involved in substitute activities that to some extent may take the place of the former occupation.

A great deal of attention has been paid to the impact of retirement on leisure participation. Leisure should provide relaxation, diversion and development of personality. If it doesn't provide at least one of the three functions, then it is outside the definition of leisure (Dumazedier, 1982).

In a study by Bhatia (1983), 40\% retired respondents experienced additional time at their disposal and were finding it difficult to utilize it in a satisfactory way. Hence there is a need for using leisure time appropriately so as to provide self-fulfillment and also maybe expand job opportunities.

\section{Retirement and Adjustment}

The concept of adjustment is a universal one, but in practice it is always specific to some concrete situations. Authors like Ramamurti (1987) prefer to study it from specifications like areas of home, health, emotional life, self concept and social life. Several theories of adjustment with relation to retirement have emerged.

\section{Activity theory}

The term job has different meaning depending upon the person and to successfully adjust for job loss is by substituting with it by a personal goal. Friedman and Havighurst (1954) are the proponents of this theory. Shanas (1972) found it to be of limiting utility in American Society.

\section{Continuity theory}

This theory says that individual copes up with retirement by spending more time in the roles he was playing before than by finding new roles to play (Atchley, 1976). It is a well known fact that most retired people like to live their retired life in a way which resembles their pre-retirement life.

\section{Disengagement theory}

Cumming and Henry (1964) hold that retirement is a necessary manifestation of the mutual withdrawal of society and older individuals from one another as a consequence of the increased prospect of biological failure in the individual organism. This theory is criticized for making the rejection of older people by society seem natural and thus 'right'. Streib and Schneider (1972) have redefined this term to 'differential disengagement' i.e. it can occur at different rates for different roles. They feel that by removing the necessity for 
energy sapping labor on a job, retirement may free the individual with declining energy to increase his level of engagement in other spheres of life.

Adjustment must be looked at in sociological and individual terms. Successful adjustment means that the individual must find self-fulfillment through socially acceptable means. As yet, our society does not accord the same positive values to retirement that it accords to work. Instead there is a tendency to look on retirement as a benchmark signifying declining physical and mental process and impending death. One of the reasons why adjustment is a problem is that society has not defined clearly those socially acceptable means whereby the retired person may find self-fulfillment. This point to the need to institutionalize retired status.

Cottrell and Atchley (1969) found that nearly 30\% felt they could never get used to retirement and this percentage was higher amongst retired teachers. Streib and Schneider (1971) classified $70 \%$ of their population as not being completely satisfied with retirement. Difficulty in adjusting to retirement included financial problems $(40 \%)$, health problems (28\%), missing ones job (22\%) and death of spouse (10\%) in a study by Riley and Foner (1965). Studies in India have shown that older people have greater problems in areas of emotional, social, health and home adjustments, in that order (Singh, 1983, Ramamurti, 1970)

Man should create for himself a pattern of activities, which serves as an effective substitute for his job (Thomson, 1958). Studies by Thomson, Streib and Kosa (1960) aim to measure adjustment in terms of satisfaction with life situation, dejection and hopelessness. They found an ordered relationship between the 3 indices.

\section{Type of job and adjustment}

White-collar workers value work and retirement more positively as compared to blue-collar workers. This is because a white-collar worker has greater attachments to his work, hence, enjoying his job. He is reluctant to leave and retire. But once he does retire, his greater flexibility also facilitates adjustment and gets other interests to substitute for his job. This is in contrast to the blue-collar worker attitude.

Thus the blue-collar worker is a victim of the retirement trap. Therefore one of the serious problems facing our society is the problem of teaching the average man how to use his leisure, because the key to successful use of leisure is the key to successful adjustment to retirement (Atchley, 1976).

Simpson (1966) has cited that type of job also depends on education. Education increases an individual's repertoire of skills and interests. When a well-educated individual, faces a difficult transition, he has a greater variety of activities to turn to, thus leading to a better adjustment. However professions like medicine, law, journalism do not pose retirement anxieties as they do not pose a serious threat in retirement (Paintal, 1977)

\section{Adjustment and Personality}

People who have a low tolerance for any change are generally the ones who have difficulty adjusting. Personality differences are also likely to play a major role. Older people's belief about how well equipped they feel they are to deal with demands of change in old age and their view on how much support they can call upon, are likely to exert an important influence on their capacity to deal with change and adjust positively to it. Personality factors considered include high levels of self-efficacy (Bandura, 1977), internal locus of control (Rotter, 1966), and a belief in one' s ability to master new situations and positive expectations about life's possibilities after retirement.

\section{Adjustment and Self}

Knowledge of self-acceptance is central to successful aging. Change in personality in old age largely comes from changes of individual concept of self. A positive self-concept goes a long way in helping a person to adjust to stress and strain of aging (Ramamurti, 1987). Back and Guptill (1966) studied self-concept between retirees and working populations and found that self-concept which involved dimensions like involvement, optimism and autonomy was lower for retirees. The decline in perception of self is entirely from loss of work. However, self-esteem showed no difference in retirement population.

They also found that retirement led to an alteration in self-concept. Older working population did not consider themselves to be old as compared to retired population. Self-concept is a significant factor in determination of interpersonal relationships. The change in self-concept accompanying retirement often isolated the retired person from others because of his tendency to see himself as old.

Streib found significant differences in the level of morale of those retired and those employed. $38 \%$ scored low on morale in working group as compared to' $62 \%$ in the retired group. Factors that affected morale were work status, socio-economic status and health. Anantharaman (1980) in his study found that retired subjects who had positive self-concept had better adjustment.

\section{Adjustment and Religiosity}


Religious beliefs also play an important role for better adjustment in old age. Religiousness in terms of belief in life after death gives a sense of 'ongoingness' and as Sharma and Jain (1987) have found, makes the old people less afraid of impending death.

It releases them from tension and worry of worldly affairs and gives mental peace and satisfaction. It also provides activities to pass their leisure time. However Russell (1979) states that there is no clear-cut evidence that religion itself contributes to the psychological well being of the aged.

\section{Retirement and Gender Differences}

Research studies on retirement often concentrated on men's life till a few years ago. Earlier women's retirement decisions were strongly influenced by their husband's health and retirement status. Today the changing conditions reflect in their expectations (Honig, 1998).

Huriock (1976) believed that the process of adjustment to retirement is greatly affected by gender to which the retiree belongs. According to his work, women on the whole take retirement in a better way than men. There is no radical role change in women for the most part have always played a domestic role in addition to their working roles. Second, because work provides fewer psychological benefits and social supports for women, retirement is less traumatic than it is for men. Jaslow (1976) also concurs with this, providing a third possible explanation that because few women have held executive positions; they do not feel that they have suddenly lost all the power and prestige.

However, Indian research studies by Nandhini et al (1996) have shown that retired men and women were equally adjusted in health, social and emotional life. There were also no differences found in depression. This probably may be because of our Indian cultural family system. But Bernard and Weir (1992) claim that men have more chances of being depressed than women are.

Well-adjusted retired women are those who enjoy a fair degree of good health, have positive health attitudes, accept age changes, maintain an even amount of emotional balance and good transaction with family members (Jamuna, 1989).

For the professional women, retirement may mean the much longed-for rest, relief from a daily schedule, the chance to do what she pleases or it may be an unwanted change which she feels offers her no challenge and prevents her from carrying on what she had intended to be her life's work (Streib, 1959). Similarly Merill (1976) has also found that as compared to older men, older women who were found to be as workoriented are more likely to take a longer time adjusting to retirement.

Older women were more likely to report "Negative" psychological symptoms, while older men were more likely to see changes in social participation. A study by Mercier et al (1996) also showed that women who had retired had lower self-esteem and thus a lesser sense of control than their working female counterparts.

\section{Employment in Older Workers}

There are people who look forward with anticipation to retirement and make plans for their retirement years. When they reach that age, they leave the labor force not because of ill health, nor because they are forced to but because they want to retire. However a category of people don't believe in this concept of mandatory retirement.

Men who enjoy working sincerely are reluctant to retire and self-employed professionals and businessmen frequently have no intention of retiring. Men who find their jobs uninteresting are most likely to want to retire. Other men continue to work, not because work is important but because it is important for them to continue working. Work for them is a source of self-respect. They resist retirement because they fear the resulting isolation. Others associate retirement with declining physical and mental health and cling to work as a form of denial of the inevitable.

The concept of older workers is a highly relative one. There are striking differences from occupation to occupation and industry to industry in the age at which "older worker" term is applied. Occupations that require physical exertion, limits employment to younger workers and those that require long periods of experience are more likely to accept older workers.

The point at which a worker becomes old is relative to the occupation considered and context in which work is performed. Self employed workers are common amongst older age categories, who are in a skilled or proprietary occupation (Schneider, 1972).

According to studies by Friedmann and Havighurst (1954) work serves five functions:

- Provides an individual with income or economic return

- Regulates a person's pattern of life activity

- Bestows status on a person within his group

- Fixes his pattern of association with other people

- It offers the worker a meaningful set of life experiences 
Findings by the researchers suggest that those who attached extra economic meaning to work were most reluctant to retire and those who looked upon work as a means of earning a living looked forward to retirement.

Singh (1982) gives the functions of work in a man's life. It provides a source of self-esteem, achievement or an outlet for creativity. It provides a system of inter personal relationships, a source of activity or an escape from difficult circumstances. It provides many things, which are not readily articulated because they relate to unconscious reasons for seeking a particular kind of work.

Some people return to a job even after having retired. It gives them an income, regulates activity and gives purpose to life. Lawton (1951) suggests that employment is the key to happiness and well being, and feels humans should be yet red' instead of retired.

Most studies have found that people who involve themselves in meaningful work after retirement are more satisfied with life and also adjust better to retired life. (Gormly, 1989) Thus retirement should not always be considered as a crisis. The period of retirement provides greater freedom and flexibility, a time to reorganize one's life and interests. The crisis can are often be ameliorated by substitute satisfactions (Goode, 1977).

\section{Voluntary Retirement}

"A man willing but unable to work is perhaps the saddest sight that fortune exhibits under the sun."

Voluntary retirement means a worker leaving his job before his attending retirement age. In the Indian Industrial Sector the word VRS (Voluntary Retirement Scheme) received legislative recognition in 1953 which differentiated it from retrenchment.

Fields (1971) observed that employers often welcome early retirement schemes as a means of controlling the size of their work force. He found that more than $10 \%$ of the retirement is actually involuntary. Employers thus used VRS as a means of getting workers to do 'voluntarily' what they wanted i.e. leave their job. The scheme is a better chance than retrenchment. But Guha (1997) found that workers were mostly compelled by circumstance in spite of giving various reasons. Some reasons why a company opts for VRS are:

- Surplus labor

- Technological developments

- Legal difficulties

- $\quad$ Sick units (Sinha, 1994)

Some reasons why people opt for VRS are:

- To purchase land or house

- $\quad$ Pay debts

- Marriage of dependent family members

- Health problems

- Fear of closure (Jani, 2000)

\section{Voluntary retirement and psychiatric morbidity}

Sethi (1982) studied how voluntary retirement can lead to numerous stressors like loss of work, decrease in income, lowered position in society and family responsibilities. Failure of contemporary urban society to provide meaningful and satisfying roles for the aged can lead to loss of direction in life.

The concept of normal retirement and now voluntary retirement has come up because of a decline in employment due to low growth and weakness of demand. The most important factor is the use of labor saving devices resulting in decline of employment (Aldcroft, 1984). Thus, VRS is being used to restore balance between labor supply and requirement.

\section{Relations with family members}

Studies by Guha (1997) found that those people who had financial consultations with family members and their own activities prior to taking VRS had better relations with family members. $81 \%$ stated no change in social structure, but they were mostly from middle socio-economic status and were the ones who were using their time and money well. However, Streib and Schneider, (1971) have studied how forced retirement is associated with low morale in most cases. The scheme has been criticized because it causes economic hardship and mental suffering to the worker. But the study by Guha (1997) has shown that appropriate resource management can lead to a better life.

Today, with booming technological advances and rapid strides in minimizing direct human energy in production, Voluntary Retirement Schemes are here to stay. Apart from financial and job loss, it leads to mental disharmony because of difficulties in rehabilitation, in finding a new job and utilization of leisure time in a 
constructive manner. Thus the need of the hour for mental health professionals is counseling in issues related to retirement. They can help in retirement planning, teaching self-confidence, coping skills, etc (Sinick, 1977).

They should be counseled regarding entrepreneur skills for doing productive work later or learning vocations that can be pursued later. Also in our country central government health schemes should be extended to the retired and social security benefits should be enhanced (Menachery, 1987).

\author{
Aims and Objectives of the Study \\ Operational Definitions \\ Design of the Study \\ - Sample Description \\ - Inclusion Criteria \\ - Exclusion Criteria Tools and Instruments Procedure
}

II. Methodology

Statistical Analysis

Aims and Objectives

The broad objective of the present study is to explore the impact of retirement on psychological well being of elderly population.

\title{
Specific Aims and Objectives of the Study
}

- To explore the adjustment in lifestyle of normally retired, voluntarily retired and working population (above the age of 60 years).

- To study life satisfaction amongst normally retired, voluntarily retired and working population (above the age of 60 years).

- To compare the mood disturbances amongst normally retired, voluntarily retired and working population (above the age of 60 years).

- To evaluate and compare self- esteem amongst normally retired, voluntarily retired and working population (above the age of 60 years).

- To study gender differences in normally retired, voluntarily retired and working population (above the age of 60 years) in the areas of adjustment, life satisfaction, depression and self-esteem.

\section{Operational Definitions}

Aging: It is defined as the process of growing old regardless of chronological age. It is a continuous process that begins at conception and eventually ends with death (Birren, 1959).

Normal Retirement: It occurs at 58- 60 years of age when a person starts to retreat, to recede or withdraw from a working professional life.

Voluntary Retirement: It is the retirement which occurs before the stipulated age (Sinha, 1994).

Working Population: Professionals who are still employed (self-employed or for an organization) due to their professional skills after 60 years of age, are taken as working population.

\section{Design of the Study}

The present study is an exploratory research using an ex-post facto design. The aim is to explore the facts as they exist by measuring the variables under study, involving respondents who are drawn from a representative population. For the purpose of the study, three groups of respondents were chosen:

- To represent normally retired population

- To represent subjects who undertook voluntary retirement earlier than the normal retirement age.

- Normal controls working after the age of 60 years.

\section{Sample Description}

A purposive sampling technique was utilized to select appropriate study groups. Nearly 100 respondents from various Districts in Tamil Nadu State. Were personally approached, out of these 76 respondents gave valid responses to form the basis of this study.

Selection of the subjects was dependent on the willingness and cooperation of the respondents.

26 respondents belonged to Normally Retired Population (NRP). 
26 respondents belonged to Voluntary Retired Population (VRP).24 respondents belonged to Working Population (WP).

\section{Inclusion Criteria}

- $\quad$ Belonged to the appropriate age group as per the requirement i.e. normal retirement more than 58 years and working more than 60 years. In voluntary retirement group there were no age limits.

- Comprehend English or Tamil speaking so as to respond to the questionnaires which had questions in English or Tamil or explained in Tamil.

- The respondents of Working Population were people who were self employed or working for an organization and were involved full time due to their professional skills.

- The working populations were individuals who continued to work with no retirement phase.

- The voluntary retirement groups were the individuals who opted for retirement before the stipulated time and in view of other limited options

- Minimum one year period of post retirement.

\section{Exclusion Criteria}

- Uncooperative respondents

- Status of retirement or working ambiguous

- Language problems

- History of known mental illness

\section{Tools and Instruments}

To achieve the objective of the study, the following tools and instruments were used:

\section{Adjustment inventory}

This was especially constructed to suit Indian cultural needs and for individuals more than 50 years of age (Ramamurti, 1968). This inventory deals with the concept of adjustment, which is suitable to the Indian context and has been accepted for the present study.

The inventory has 100 terms to which the subject had to respond either by yes or no. The inventory covers the area of health, emotional life, self, home and social life. The scores indicate the degree of maladjustment. The mean of each component is taken as the cut off point for that population of maladjustment. Test-retest reliability gave coefficient of 0.88 .

\section{Life satisfaction scale}

It is constructed by Robert J Havighurst (1963) to measure life satisfaction of aged people. Havighurst considered life satisfaction as a better index of success and the scale gives information whether a person is satisfied with his or her life. The scale contains 20 statements and individuals have to give that opinions by 3 responses i.e. agree, disagree or cannot say. Each has a score of 0,1 and 2 and the sum of scores is taken. Range of scores is from 0-40.

- $\quad$ Scores of 20-30 average life satisfaction

- 30 - 35 above average life satisfaction

- Less than 30 below average life satisfaction.

Test retest reliability is $0.78\left(\mathrm{r}^{++}=0.78\right)$. Correlation coefficient between life satisfaction scale and Chicago attitude inventory was found to be $0.58\left(\mathrm{r}^{++}=0.58\right)$

\section{Mood questionnaire:}

Brummel - Smith, K. in Yoshikawa T.T. (1993) Ambulatory Geriatric Care, developed this questionnaire. It consists of 22 items having true or false responses. In the absence of normative data, group mean was considered as a cut-off point to differentiate the groups on high and low levels of mood. Higher the scores, the possibilities of having mood disturbances (depression) increases.

\section{Index of self esteem questionnaire:}

This questionnaire is developed by Hudson (1982) and consists of 25 items. It measures degree and magnitude of self-esteem. High scores (above 30) indicate low self esteem and converse is true for low scores. The author has reported high split-half and test-retest reliability along with content and criterion validity.

\section{Socio-demographic questionnaire:}

Structured questionnaire specifically prepared for the study. 


\section{MINI}

The M.I.N.I. was designed as a brief structured interview for the major Axis I psychiatric disorders in DSM-IV and ICD-10. Validation and reliability studies have been done comparing the M.I.N.I. to the SCID-P for DSM-III-R and the CIDI (a structured interview developed by the World Health Organization for lay interviewers for ICD-10). The results of these studies show that the M.I.N.I. has acceptably high validation and reliability scores, but can be administered in a much shorter period of time (mean $18.7 \pm 11.6$ minutes, median 15 minutes) than the above referenced instruments. It can be used by clinicians, after a brief training session. Lay interviewers require more extensive training.

\section{Procedure:}

After selecting suitable instruments to measure desirable characteristics of the respondents all the participants were individually approached according to the above criteria with a request letter to cooperate for the study. Informed consent was taken. Some of the respondents immediately filled the proforma and questionnaire whereas others returned them according to their convenience. Many of the respondents did not complete the entire proforma thus resulting in dropouts, as they found the questionnaire lengthy and did not seem motivated or interested. Although complete confidentiality was assured, some of the respondents did not cooperate as they felt their personal life would be exposed. A few of the respondents have written personal comments (appreciative as well as critical) regarding the questions.

\section{Statistical Methods}

Data was hand scored and tabulated and later computerized. Statistical package of social sciences (SPSS) was used to analyze the findings. Independent' $t$ ' test and one way Analysis of Variance (ANOVA) were applied. The level of significance for acceptance of result was set at 0.05 levels. 'F' test is applied when one has to analyze the mean differences between more than two group' $s$ and' $t$ ' test is applied when one has to analyze the mean differences between two groups with only a single independent variable. These statistical techniques are known as univariate inferential statistics.

\section{Results And Discussion}

This chapter brings out the main findings of the research study. Results have been analyzed and interpreted on the basis of different normative cutoff points as described by the authors of the scales. Data was subjected to SPSS-Statistical package for social sciences. One Way ANOVA and T test were carried out, and level of significance was decided at 0.05 levels as critical value.

\section{Socio Demographic Profile}

Table 1: The three groups are labeled as: NRP-Normally retired population (superannuation) VRP-Voluntary retired population WP-Working population (above 60yrs)

\begin{tabular}{|l|c|c|l|}
\hline \multicolumn{2}{|c|}{ NRP $(\mathrm{n}=26)$} & $\mathbf{V R P}(\mathrm{n}=26)$ & \\
\hline Gender & & 11 & 16 \\
\hline Males & 15 & 15 & 8 \\
\hline Females & 11 & $1(3.8 \%)$ & \\
\hline Ages & - & $16(61.5 \%)$ & - \\
\hline 40 - 50 years & $4(15.4 \%)$ & $9(34.6 \%)$ & $24(100 \%)$ \\
\hline $51-60$ years & $22(84.6 \%)$ & & \\
\hline$>60$ years & & $9(34.6 \%)$ & $5(20.8 \%)$ \\
\hline Education & $10(38.5 \%)$ & $12(46.2 \%)$ & $5(20.8 \%)$ \\
\hline Undergraduate & $9(34.6 \%)$ & $5(19.2 \%)$ & $14(58.4 \%)$ \\
\hline Graduate & $6(23.1 \%)$ & & \\
\hline Postgraduate & & & \\
\hline
\end{tabular}

\begin{tabular}{|l|c|c|l|}
\hline & NRP(n=26) & VRP $(\mathrm{n}=\mathbf{2 6})$ & $\mathrm{WP}(\mathrm{n}=24)$ \\
\hline Marital Status & & & \\
\hline Married & $18(69.2 \%)$ & $21(80.8 \%)$ & $22(91.7 \%)$ \\
\hline Unmarried & $6(23.8 \%)$ & $1(3.8 \%)$ & - \\
\hline Widowed & $2(7.7 \%)$ & $4(15.4 \%)$ & $2(8.3 \%)$ \\
\hline Religion & & & \\
\hline Hindu & $20(76.9 \%)$ & $22(84.6 \%)$ & $17(70.8 \%)$ \\
\hline Muslim & - & $1(3.8 \%)$ & \\
\hline Christian & $4(15.4 \%)$ & $1(3.8 \%)$ & $6(25 \%)$ \\
\hline Others & $2(7.7 \%)$ & $2(7.7 \%)$ & $1(4.2 \%)$ \\
\hline Monthly income (Rs.) & & & \\
\hline$<5000$ & $10(38.5 \%)$ & $4(15.4 \%)$ & $1(4.2 \%)$ \\
\hline $5000-10,000$ & $4(15.4 \%)$ & $8(30.8 \%)$ & $2(8.3 \%)$ \\
\hline $10,000-15,000$ & $3(11.5 \%)$ & $8(30.8 \%)$ & $6(25 \%)$ \\
\hline
\end{tabular}




\begin{tabular}{|l|c|c|l|}
\hline $15,000-20,000$ & $4(15.4 \%)$ & $3(11.5 \%)$ & $4(16.7 \%)$ \\
\hline Salary at the time of Retirement & $5(19.2 \%)$ & $3(11.5 \%)$ & $11(45.8 \%)$ \\
\hline Adequate & & & \\
\hline Inadequate & $6(23.1 \%)$ & $21(80.8 \%)$ & Not applicable \\
\hline Can't say & $1(3.8 \%)$ & $5(19.2 \%)$ & \\
\hline Other retired Members & & & \\
\hline Yes & $5(19.2 \%)$ & $4(15.4 \%)$ & $6(25 \%)$ \\
\hline No & $21(80.8 \%)$ & $22(84.6 \%)$ & $18(75 \%)$ \\
\hline Years of retirement & $26(100 \%)$ & $26(100 \%)$ & Not applicable \\
\hline less than one year & & & \\
\hline
\end{tabular}

From Table 1 the following sociodemographic features are illustrated.

\section{Sex ratio}

There were 17 males and 10 females in NRP, 14 males and 11 females in VRP and 17 males and 7 females in WP.

\section{Age}

In NRP $4(15.4 \%)$ were 51-60 years and $22(84.6 \%)$ were more than 60 years.

In VRP only 1 (3.8\%) was less than 50 years while $15(61.5 \%)$ and $9(34.6 \%)$ were more than $50-60$ years and more than 60 years respectively. In WP, according to the objectives all the respondents' i.e. $24(100 \%)$ were more than 60 years.

\section{Education}

In NRP, $11(39.5 \%)$ were undergraduates, $10(35.6 \%)$ were graduates and 6(23.1\%) were postgraduate.

In VRP, $10(35.6 \%)$ were undergraduates, $11(45.2 \%)$ were graduates and $4(18.2 \%)$ were postgraduate.

In WP $5(20.8 \%)$ were undergraduate and graduate with $5(20.8 \%)$. postgraduates $14(58.4 \%)$ This probably explains why they were still working.

\section{Marital Status}

In NRP, $19(70.2 \%)$ were married, 5(22.8\%) were unmarried and $3(14.4 \%)$ were widowed. In VRP, 21(80.8\%) were married, 1(3.8\%) was unmarried and 3(14.4\%) were widowed. On the other hand $21(90.7 \%)$ were married and $2(8.3 \%)$ widowed, unmarried 1(3.8\%)

\section{Religion}

In NRP, there were 20(76.9\%) Hindus, 5(16.4\%) Christian and were Muslim 1(3.8\%), 1(3.8\%) belonging to other communities.

In VRP, there were 22(84.6\%) Hindus, 1(3.8\%) Muslim, 1(3.8\%) Christian and 1(3.8\%) belonging to other communities.

In WP, there were 17 (70.8\%) Hindus, 5(25\%) Christian and 1(4.2\%) belonging to other communities were Muslim 1(4.1\%)

\section{Monthly Income}

In NRP, 10 (38.5\%) had monthly income of < 5,000 with 5 (16.4\%) having income between Rs. 5000$10,000,4(12.5 \%)$ having income between 10,000-15,000, 6 (15.4\%) having income of 15,000-20,000 and $3(11.5 \%)$ with income of more than 20,000 .

In VRP, 8 (30.8\%) had income of Rs. 5,000-10,000 and Rs. 15,000-20,000, with 4(15.4\%) having income of < 5000 and $4(15.5 \%)$ having incomes of $15,000-20,000$ and $>20,000$ respectively.

In WP, they had $11(45.8 \%)$ having income of Rs. 20,000 and only $1(4.2 \%)$ having income of $<$ Rs. 5,000. 2(8.3\%) had income of 5,000-10,000, 5(24\%) had Rs. 10,000-15,000 as income and $5(17.7 \%)$ had income of Rs. 15,000-20,000. This shows how working even after retirement keeps a person at a high-income level.

\section{Salary at the time of retirement}

In NRP, $19(73.1 \%)$ felt that their salary was adequate and 6(23.1\%) felt it was inadequate. $2(8.3 \%)$ can' $t$ say In VRP, $21(80.8 \%)$ felt that their salary at the time of voluntary retirement was adequate and only $4(18.2 \%)$ felt that salary they received was inadequate. This component does not apply to the still working population. The above finding may probably be because the sample taken was from a middle socio-economic 
background. However this does not prove whether respondents suffered from economic problems or not because of the loss in income, although the retirement pension was adequate.

\section{Other retired family members}

In NRP, there were 6(20.2\%) respondents who had other retired family members $21(80.8 \%)$ respondents did not have other retired family members. In VRP, there were only $5(19.4 \%)$ individuals, who had other retired family members living with them, whereas 20(82.4\%) individuals did not have any other retired family members in the house. This probably could be explained on the basis that either they were living in a nuclear family or their spouse was still working.

In WP, there were 6(25\%) individuals who had other retired family members while $18(75 \%)$ individuals did not have other retired family members.

\section{Years of retirement}

In NRP, 27(100\%) were retired for less than one year. In VRP, 3(11.5\%) had retired for less than one year, $9(34.6 \%)$ had retired between one to five years and $14(53.8 \%)$ had retired for more than five years.

\section{Adjustment Inventory}

Comparison of Health amongst NRP. VRP and WP

Table 2: Means, 'F' Ratio, DF (Degree of freedom) and level of significance between normally retired population (NRP), voluntarily retired population (VRP) and working population (WP).

\begin{tabular}{|l|c|r|r|r|}
\hline Groups & Scores Mean & Df & 'P & Significance \\
\hline NRP & 3.76 & & & \\
\hline VRP & 5.19 & $2 / 73$ & 2.3 & $\mathrm{p}<0.10$ \\
\hline WP & 3.2 & & & \\
\hline Group mean & 4.07 & & & \\
\hline
\end{tabular}

The findings in table II expressed the means obtained in the area of health of the adjustment inventory. The 'P Ratio (' $F$ ' $=2.3$ and $p<0.10$ ) indicated that the ' $F$ ' value was not significant at 0.05 level but being 0.10 , showed certain trends in the area of health. If group mean was taken as critical value to show high and low adjustment in the area of health,

\section{VRP clearly showed symptoms of having poorer health in comparison to NRP and WP.}

In the area of health, it was voluntary retirement group who reported/perceived more health related difficulties e.g. skin eruptions, renal problems, multiple somatic complaints, pain and hypertension and diabetes mellitus. One cannot explain whether these are psychosomatic or not. According to Ellison (1968) illness after retirement is a psychosomatic ploy used as justification for becoming dependent on children. However Ostberg (1994) instead found retirement to have positive influence on health and not worsening diseases like hypertension. According to Mohanty (1989) financial reasons, negligence, lethargy and casual attitude of retired people for medical checkups cause health problems. McMichael and Tyroler (1977) found that mortality increased after compulsory retirement among workers.

\section{Gender differences in NRP. VRP and WP on health}

Table 3: Means, standard deviation (SD),' t' value and level of significance of normally retired population (NRP), voluntarily retired population (VRP) and working population (WP)

\begin{tabular}{|c|c|c|c|c|c|}
\hline \multirow[t]{2}{*}{ Groups } & \multirow[t]{2}{*}{ Sex ratio } & \multirow[t]{2}{*}{ Mean X } & \multirow[t]{2}{*}{ SD } & \multirow[t]{2}{*}{$\cdot t^{\prime}$} & Significance \\
\hline & & & & & off \\
\hline \multirow[t]{2}{*}{ NRP } & $\mathrm{M}=15 \mathrm{~F}=11$ & 3.24 .54 & 3.36 & -1.0 & $\mathrm{p}<0.32$ \\
\hline & & & 3.38 & & \\
\hline \multirow[t]{2}{*}{ VRP } & $\mathrm{M}=15 \mathrm{~F}=11$ & 3.636 .33 & 3.04 & -1.80 & $\mathrm{p}<0.08$ \\
\hline & & & 4.57 & & \\
\hline WP & $M=16 \mathrm{~F}=8$ & 3.253 .12 & 2.41 .2 & 0.16 & $\mathrm{p}<0.87$ \\
\hline
\end{tabular}

The findings in table 3 expressed the means obtained in the area of health of the adjustment inventory to illustrate gender differences in this aspect. Although no significant differences were noted at 0.05 level but certain trends were seen. VRP showed that women had symptoms of poorer health in comparison to men $(\mathrm{T}=-1.80, \mathrm{p}<0.08)$. There were no gender differences seen in NRP and $\mathrm{WP}\left({ }^{\prime} \mathrm{t}\right.$ ' $=-1.0, \mathrm{p}<0.32$ and $\mathrm{T}=0.16$, $\mathrm{p}<0.87$ ). This may be because of the age of women in VRP coinciding with their menopausal age leading to poorer perception of health or sudden transition in lifestyle causing more stress and maybe psychosomatic 
illness. Belgrave (1987) analyzed that presence of chronic health conditions was related to early retirement for men but not for women. This is contrary to the above findings.

\section{Comparison of Emotional life amongst NRP. VRP and WP}

Table 4: Means, 'F Ratio, Df and level of significance between normally retired population (NRP), voluntarily retired population (VRP) and working population (WP).

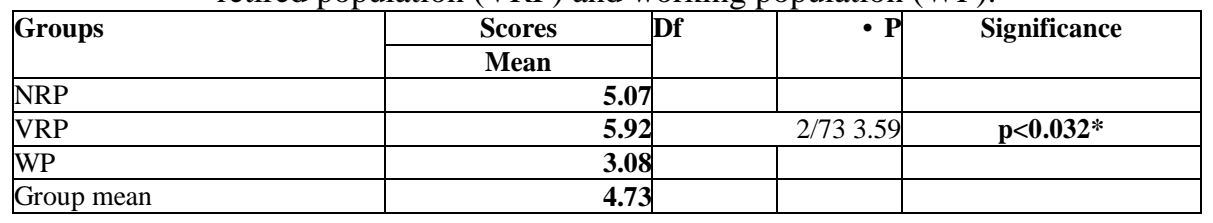

The findings in table 4 expressed the means obtained in the area of emotional life of the adjustment inventory. The 'F Ratio ('F'= 3.59 and $\mathrm{p}<0.032$ ) indicated that the groups differed significantly from each other. If group mean was taken as critical value to show high and low adjustment, then WP showed comparatively better adjustment in relation to emotional well being as compared to VRP and NRP. In the area of emotional life adjustment it was both the retired groups who showed difficulty in adjusting towards emotional life. The retirement groups felt mood swings, worries about the future, tense and nervous, inferiority feelings, loneliness and boredom. These findings were also observed in the section where the mood questionnaire was discussed. Retirement is one of the factors attributing to depression in old age whereas work is therapeutic (Agarwal, 1998).

Gender differences in NRP. VRP and WP on Emotional life

Table 5: Means, standard deviation (SD), T value and level of significance of normally retired population (NRP), voluntarily retired population (VRP) and working population (WP)

\begin{tabular}{|l|l|l|r|r|r|}
\hline Groups & Mean $\mathbf{X}$ & SD & & Significance \\
\cline { 4 - 6 } & & & 3.92 & -0.33 & off \\
\hline NRP & M=15 F=11 & 4.865 .36 & 3.61 & & \\
\hline & & & 3.38 & -1.60 & 0.74 \\
\hline VRP & M=15 & 4.36 & 5.39 & & \\
\hline & $\mathrm{F}=11$ & 7.06 & 3.04 & -0.07 & 0.10 \\
\hline WP & $\mathrm{M}=16 \mathrm{~F}=8$ & 3.063 .12 & 1.45 & & \\
\hline & & & & & \\
\hline
\end{tabular}

As seen in table 5, in the area of emotional life, although no significant differences were noted at 0.05 level but certain trends were seen. The VRP group showed that women had more difficulty in adjustment in relation to emotional wellbeing as compared to men $(T=-1.60, p<0.10)$. No significant differences were noted in NRP or WP $(T=-0.33, \mathrm{p}<0.74$ and $\mathrm{T}=-0.7, \mathrm{p}<0.94)$. Hollis (1998) found that although no significant differences

Were noted in mean life satisfaction scores, retired women were lower in adjustment scores than men i.e. they were more likely to express regret and sometimes frustration towards perceived missed opportunities in life (career) due to their expected social roles of being a wife and a mother. This study corroborates the above findings.

Self: Comparison of Self Worth and Usefulness amongst NRP. VRP and WP

Table 6: Means, 'F' Ratio, DF and level of significance between normally retired population (NRP), voluntarily retired population (VRP) and working population (WP).

\begin{tabular}{|l|l|l|l|l|}
\hline Groups & Score Mean & Df & .F & Significance \\
\hline NRP & 5.53 & \multicolumn{2}{|c|}{} & \\
\hline VRP & 5.26 & 2.733 .62 & $\mathrm{p}<0.03^{*}$ \\
\hline WP & 3.66 & & & \\
\hline Group mean & 4.85 & & & \\
\hline
\end{tabular}

The findings in table 6 expressed the means obtained in the area of self worth which is a part of the adjustment inventory. The "F Ratio (' $F=3.63, \mathrm{p}<0.03$ ) indicated that the groups differed significantly from each other. If group mean was taken as critical value to show high and low adjustment, then WP showed better adjustment in relation to self (i.e. better feelings of self worth arid usefulness) as compared to the two retirement populations.

In the area of self, it was seen that working groups had shown favorable trends. Thus it could be inferred that irrespective of the type of retirement, self worth had downward tendency as compared to the 
control peers of the same age. Individuals who were not professionally active felt lack of competency, low selfesteem, low self-concept, lack of self-respect and feelings of being unwanted and were also lower in achievement motivation. Supporting evidence was corroborated in studies by Back and Guptill (1966) who found that self concept which involved dimensions like involvement, optimum and autonomy was lower for retirees. Thus decline in perception was entirely from loss of work. Chown (1970) feels morale is often lower among retired than those working, however Streib and Schneider (1971) feel that low morale is a long term condition and not due to effect of retiring.

Gender differences in NRP. VRP and WP on Self Worth and Usefulness

Table 7: Means, standard deviation (SD), " $t$ " value and level of significance of normally retired population (NRP) voluntarily retired population (VRP) and working population (WP)

\begin{tabular}{|c|c|c|c|c|}
\hline \multirow[t]{2}{*}{ Groups } & \multirow[t]{2}{*}{ Sex ratio } & \multirow[t]{2}{*}{ Mean X } & \multirow[t]{2}{*}{ SD } & \multirow{2}{*}{$\begin{array}{c}\text { Significance } \\
\text { off }\end{array}$} \\
\hline & & & & \\
\hline \multirow[t]{2}{*}{ NRP } & $\mathrm{M}=15 \mathrm{~F}=11$ & 5.066 .18 & \begin{tabular}{l|l|}
2.65 & -0.92
\end{tabular} & $p<0.36$ \\
\hline & & & \begin{tabular}{|l|l|}
3.31 & \\
\end{tabular} & \\
\hline \multirow[t]{2}{*}{ VRP } & $\mathrm{M}=15 \mathrm{~F}=11$ & 4.455 .86 & 2.651 .26 & $\mathrm{p}<0.21$ \\
\hline & & & \begin{tabular}{l|l}
3.02 \\
\end{tabular} & \\
\hline \multirow[t]{2}{*}{ WP } & $M=16 \mathrm{~F}=8$ & 3.54 .0 & \begin{tabular}{l|l|}
$1.78-0.57$ \\
\end{tabular} & $\mathrm{p}<0.58$ \\
\hline & & & \begin{tabular}{l|l}
2.13 & \\
\end{tabular} & \\
\hline
\end{tabular}

The findings in table 7 expressed the means in the area of self worth of the adjustment inventory in differences between genders. The above findings showed that there were no significant gender differences in NRP, VRP and WP $\left(T=0.92, \mathrm{p}<0.36,{ }^{\prime} \mathrm{t}\right.$ ' $=-1.26, \mathrm{p}<0.21$ and ' $\mathrm{t}$ ' $\left.=0.57, \mathrm{p}<0.58\right)$. This showed that both men and women did not show any significant differences in their feelings of self worth or feeling of self-concept in the three groups.

\section{Home: Comparison of Relationships with Family Members amongst NRP. VRP and WP}

Table 8: Means, 'F' Ratio, DF and level of significance between normally retired population (NRP), voluntarily retired population (VRP) and working population (WP).

\begin{tabular}{|l|l|r|r|r|}
\hline \multirow{2}{*}{ Groups } & Scores & Df & $\bullet \mathbf{P}$ & \multicolumn{2}{c|}{ Significance } \\
\cline { 2 - 3 } & Mean & & \\
\hline NRP & 3.73 & & & \\
\hline & & 2.73 & 3.68 & $\mathrm{p}^{2}<0.03^{*}$ \\
\hline VRP & 4.5 & & & \\
\hline WP & 1.7 & & & \\
\hline Group mean & 3.35 & & \\
\hline
\end{tabular}

Table 8 expressed the means obtained in the area of home relationships of the adjustment inventory. The 'F' Ratio ('F = 3.68, $\mathrm{p}<0.03$ ) indicated that the groups differed significantly from each other. If the group mean was taken as a critical value to show high or low adjustment then WP showed better adjustment in relation to home (i.e. with family members) as compared to the retired population groups.

In the area of home, people who were still working and those who had normally retired had better relation with the family members. However, people who had taken voluntary retirement felt they were subjects of criticism at home, felt irritated, dominated by family members, had frequent conflicts at home and were generally disappointed.

This could be due to the unpreparedness of voluntary retirement and spending so much time at home which was difficult to accept by the subject and their families. Mohanty (1989) states that the sudden decline in income with lack of planning leads to problems in adjustment in the family.

If a person works, he is busy and stressors with family are also reduced. Moreover if they work for an income they don't have to lead a dependent lifestyle. Singh (1983) has also found that non-working individuals had more problems in home adjustment than working. Bhatia (1983) feels that there is problem of adjustment to family life and it is because of changes on account of industrialisation and urbanization. In India, the joint family and patriarchal structure is gradually giving way due to the change in power structure and decision making being exercised by other family members. 


\section{Gender differences in NRP. VRP and WP on Home (Family relationships)}

Table 8: Means, standard deviation (SD),' t' value and level of significance of normally retired population (NRP), voluntarily retired population (VRP) and working population (WP)

\begin{tabular}{|l|l|r|r|r|r|}
\hline Groups & Sex ratio & Mean X & SD & \multicolumn{2}{c|}{ Significance } \\
\cline { 3 - 6 } & & & & off \\
\hline NRP & $M=15 \mathrm{~F}=11$ & 3.733 .72 & 3.84 & 0.00 & $\mathrm{p}<0.99$ \\
\hline & & & 4.05 & & \\
\hline VRP & $\mathrm{M}=15 \mathrm{~F}=11$ & 2.635 .86 & 3.00 & -1.93 & $\mathrm{p}<0.05^{*}$ \\
\hline & & & 5.44 & & \\
\hline WP & $\mathrm{M}=16 \mathrm{~F}=8$ & 1.372 .37 & 1.66 & -1.22 & $\mathrm{p}<0.24$ \\
\hline
\end{tabular}

As seen in table 9, in the area of home, significant differences were noted between men and women. In VRP, showed that men had better adjustment in relation to home (with family members) as compared to women $t=-1.93, p<0.05)$. This probably may be because of feeling of redundancy due to the sudden loss of work making it difficult for women to adapt to a housewife role. As seen in the results of the study, normally retired women were better prepared to deal with their home duties, thus having better adjustment at home. In Indian society, men are considered the head irrespective, of their working situation.

According to Muttagi (1997) normally retired women adjust better to home than men because women always play a domestic role so there is no sudden discontinuity.

\section{Comparison of Social life amongst NRP. VRP and WP}

Table 10: Means, 'F Ratio, Df and level of significance between normally retired population (NRP), voluntarily retired population (VRP) and working population (WP).

\begin{tabular}{|c|c|c|c|c|}
\hline Groups & Scores & Df & & Significance \\
\hline NRP & 6.00 & & & \\
\hline & & 2.73 & 2.69 & \\
\hline VRP & 5.58 & & & $p<0.07$ \\
\hline WP & 4.29 & & & \\
\hline Group mean & 5.31 & & & \\
\hline
\end{tabular}

The findings in table 10 expressed the means obtained in the area of social life of the adjustment inventory. The ' $F$ ' ratio (' $F$ ' $=2.69$ and $\mathrm{p}<0.07$ ) indicated that ' $F$ ' value was not significant at 0.05 level but showed certain trends. If group mean was taken as critical value to show high and low adjustment then WP showed better adjustment in social life (i.e. relation with friends and interaction in society) as compared to the retired population groups.

In the area of social life, negative trends were seen irrespective of the type of retirement although the groups did not differ significantly from each other. It could be stated that retired population were more socially inhibited, preferred to be alone, felt they could not make friends easily, were not very comfortable in social gatherings and were more self conscious. Studies in Japan by Yamashita et al (1997) have also suggested that early retirement decrease the frequency of social contacts. They recommended an extra workplace social relationship to prevent them for falling into social isolation after retirement. Paintal (1977) had also found that retired people who continued to be active were better adjusted in interactions than others. However, Maddox (1965) did not find such a positive correlation. Cummings (1960) also found that older people in general have fewer interactions with others. Similarly in a study by Bhatia (1983) only $15 \%$ were found to be socially isolated. This may be because of the nature of Indian families and our social structure.

\section{Gender differences in NRP. VRP and WP on Social Life}

Table 11: Means, standard deviation (SD),' t' value and level of significance of normally retired population (NRP) voluntarily retired population, (VRP) and working population (WP)

\begin{tabular}{|c|c|c|c|c|c|}
\hline Groups & Sex ratio & Mean X & SD & & Significance off \\
\hline NRP & $M=15 \mathrm{~F}=11$ & \begin{tabular}{|l|l|}
5.7 & 6.36 \\
\end{tabular} & 2.373 .00 & -0.58 & $\mathrm{p}<0.57$ \\
\hline VRP & $\mathrm{M}=15 \mathrm{~F}=11$ & 5.095 .93 & 2.113 .91 & -0.70 & $\mathrm{p}<0.48$ \\
\hline WP & $M=16 \mathrm{~F}=8$ & \begin{tabular}{|l|l|}
4.8 & 3.2
\end{tabular} & 1.62 .3 & 1.67 & $\mathrm{p}<0.12$ \\
\hline
\end{tabular}

As seen in table 11 in the area of social life no significant differences were noted between men and women in NRP, VRP and WP $\left(T=-0.58, \mathrm{p}<0.57, \mathrm{~T}=-0.70, \mathrm{p}<0.48\right.$ and' $\left.\mathrm{t}^{\prime}=1.67, \mathrm{p}<0.12\right)$. Thus there were no significant differences in relation to social life among the two sexes. 
Life satisfaction scale (LSS)

Comparison of Life Satisfaction amongst NRP. VRP and WP

Table 12: Means, 'F' Ratio, DF and level of significance between normally retired population (NRP), voluntarily retired population (VRP) and working population (WP).

\begin{tabular}{|c|c|c|}
\hline Groups & Scores, Df & Significance \\
\hline & Mean & \\
\hline NRP & 28.8 & \\
\hline & & $p<0.28$ \\
\hline VRP & 27.8 & \\
\hline WP & 30.4 & \\
\hline
\end{tabular}

Findings in table 12 expressed the rnean obtained on life satisfaction of individuals belonging to normally retired population (NRP), voluntarily retired population (VRP) and working population (WP). The $V$ ratio ( ' $F$ ' $=1.29, \mathrm{p}<0.28$ ) suggested that the three groups did not show significant differences from each other. However if observed carefully and looking at the scoring of life satisfaction as given on page 45, it can be seen that NRP and VRP had average life satisfaction score whereas WP had above average life satisfaction score.

Analysis of results indicated that none of the groups were dissatisfied with life, since all the categories had average values of life satisfaction. This suggested that they were enjoying their present life, did not find fife boring or uninteresting, felt that they got a good deal in life and they got what they wanted most of the time.

However the working population had obtained above average scores indicating the level of satisfaction was much better.

Aggarwal (1998) has found positive association between work involvement and life satisfaction in old age. According to Aggarwal if people are occupied in old age, the problem of loneliness, loss of status and respect, distance from productive system of society and mental health can be restored. In a study by Bhatia (1983), he found no change in life satisfaction after retirement and in fact the retirees felt peace of mind.

Dillard (1982) in his study found no change in perception of life satisfaction of retired subjects from working subjects. He also states that correlation between life satisfaction and adjustment is not always possible because life satisfaction can be taken as the internal state of the individual and adjustment as a state viewed externally. These findings corroborate with the present study. However studies by Gormly, (1989) have found that people who involve themselves in meaningful work after retirement are more satisfied with life and also adjust better to retired life.

Gender differences amongst NRP, VRP and WP oh life satisfaction scale

Table 13: Means, standard deviation (SD), T value and level of significance of normally retired population (NRP), voluntarily retired population (VRP) and working population (WP)

\begin{tabular}{|c|c|c|c|c|c|}
\hline \multirow[t]{2}{*}{ Groups } & \multirow[t]{2}{*}{ Sex ratio } & \multirow[t]{2}{*}{ Mean X } & \multirow[t]{2}{*}{ SD } & \multirow[t]{2}{*}{$\mathrm{T}$} & Significance \\
\hline & & & & & off \\
\hline NRP & $M=15 \mathrm{~F}=15$ & \begin{tabular}{|l|l|}
29.73 & 27.54 \\
\end{tabular} & $5 . 6 5 \longdiv { 7 . 7 5 }$ & 0.79 & $\mathrm{p}<0.43$ \\
\hline VRP & $\mathrm{M}=15 \mathrm{~F}=11$ & 29.1826 .93 & $\begin{array}{l}5.156 .06 \\
\end{array}$ & 1.02 & $\mathrm{p}<0.32$ \\
\hline WP & $\mathrm{M}=16 \mathrm{~F}=8$ & \begin{tabular}{l|l|l|}
30.18 & 31 \\
\end{tabular} & \begin{tabular}{l|l|l}
5.15 .5 \\
\end{tabular} & -0.45 & $\mathrm{p}<0.65$ \\
\hline
\end{tabular}

As seen in table 13, no significant differences were observed between men and women in NRP, VRP and WP in life satisfaction

$(' \mathrm{t}=0.79, \mathrm{p}<0.43, \mathrm{~T} .=1.02, \mathrm{p}<0.32$

Quick (1998) in his study has also reported very little difference in satisfaction between retired men and women. He observed that for women increased retirement quality was associated with good health, a continuous career, an early retirement and a good income.

For men the key correlates with retirement quality are good health, an enjoyable pre-retirement job, low work role salience and retiring for internally motivated reasons. 
Mood Questionnaire Comparison of Mood (Depression) amongst NRP. VRP and WP

Table 14: Means, 'F' Ratio, DF and level of significance between normally retired population (NRP), voluntarily retired population (VRP) and working population (WP).

\begin{tabular}{|c|c|c|c|c|}
\hline \multirow[t]{2}{*}{ Groups } & Scores & Df. & \multicolumn{2}{|c|}{ 'F|Significance } \\
\hline & Mean & & & \\
\hline NRP & 4.8 & & & \\
\hline & & & & $p<0.02 *$ \\
\hline VRP & 4.9 & $2 / 73$ & 3.97 & \\
\hline WP & 1.6 & & & \\
\hline Group mean & 3.85 & & & \\
\hline
\end{tabular}

The findings in table 14 expressed the means obtained in the area of mood questionnaire. The ' $F$ ' ratio ( $\left.{ }^{\prime} \mathrm{F} '=3.97, \mathrm{p}<0.02\right)$ indicated that the groups differed significantly from each other.

Thus WP differed significantly from NRP and VRP in the area of depression. As seen in the group mean (3.85), it is clearly evident that both NRP and VRP have shown tendency towards depression as compared to WP.

People from the two retired groups did not find life interesting, were unhappy, had sleep and a appetite disturbances, were tired and fatigued, felt frustrated, worthless and sad as compared to WP. Studies by Lowenthal (1964) have found that association between retirement and mental health is mainly a function of poor health, low social activity rather than retirement per se. Contrary to this Pitt (1990) has shown that retirement may contribute to depression neurosis, subjective anxiety and marital tension.

Rao et al (1996) in their geropsychiatric morbidity survey found that depressive illness contributed to $67 \%$ of the total psychiatric morbidity in the aged. Studies by Guha (1997) have shown that transition in lifestyle of VRS leads to anxiety and psychological disorders and feels that family support is necessary in such situations. Anant (1967) and Bronkey (1977) have observed symptoms of depression, frustration and anxiety. These studies suggest that this aspect of psychiatric morbidity associated with retirement needs special attention for mental health professionals.

\section{Gender differences amongst NRP, VRP and WP on Mood Questionnaire}

Table 15: Means, standard deviation (SD), $T$ value and level of significance of normally retired population (NRP), voluntarily retired population (VRP) and working population (WP)

\begin{tabular}{|l|l|l|l|r|c|}
\hline Groups & Sex ratio & Mean X & SD & & \multicolumn{2}{|c|}{ Significance } \\
\cline { 3 - 6 } & & & & & off \\
\hline NRP & $M=15 \mathrm{~F}=11$ & 4.35 .54 & 4.63 & -0.45 & $\mathrm{p}<0.66$ \\
\hline VRP & & & 8.09 & -0.47 & \\
\hline WP & $\mathrm{M}=15 \mathrm{~F}=11$ & 4.455 .26 & 3.235 .5 & -0.23 & $\mathrm{p}<0.64$ \\
\hline
\end{tabular}

As seen in table 15 in the area of depression, men and women showed no significant differences in NRP, VRP or WP $(' t '=-0.45, p<0.66 / t '=-0.47, p<0.64$ and $t$ ' $=-0.23, p<0.82)$. Although overall significant differences were noted between the retired and working population (as seen in table XIV), there were no gender differences. Midanik (1995) has found that retired women are more likely to have lower stress levels and better mental health than their non-retired counter parts.

However Ahuja (1995) has found that depression was more common in older women than in men probably because of death of spouse and low socio economic status. Our study had individuals from middle socio economic status and very few were widowed, probably explaining the lack of gender differences in depression.

\section{Index of Self Esteem}

\section{Comparison of Self Esteem amongst NRP. VRP and WP}

Table 16: Means, 'F' ratio, DF and level of significance between normally retired population (NRP), voluntarily retired population (VRP) and working population (WP)

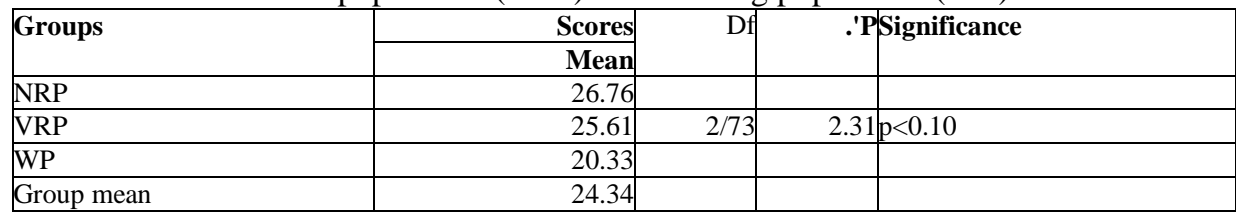

Findings in table 16 expressed the means obtained oh index of self-esteem of individuals belonging to NRP, VRP and WP. The obtained ' $F$ ' ratio ( ' F' $=2.31, \mathrm{p}<0.10$ ) indicated that the $* \mathrm{~F}$ value was not significant at 0.05 level but showed certain trends. If 30 is taken as the cutoff point, then none of the groups showed low 
self esteem, but if group mean is taken as the critical point, then VRP and NRP showed significant differences as compared to WP.

Similar findings are also observed where mood and self (in adjustment) are discussed. The retired population felt lower in competence, self-confidence, felt they were boring, uninteresting and unlikable. These all reflect lowered sense of self-esteem. Self-esteem is based on emotional assessment of self where as selfconcept is the cognitive definition of one' s identity.

The quality of self-esteem makes it more dynamic and more easily influenced by external factors like retirement, widow hood, health status etc. Thus social changes and the loss of status that accompanies them often have a negative impact on an older persons' self esteem. Hence an important adjustment method in the old age is to redefine one' s self concept as new roles are taken up. Studies have shown a generalized decrease in self-esteem between 50-80 years of age. (Kogan and Wallach, 1961)

Aldrich and Lipman (1976) have noted a reduction in feeling of confidence and personal worth among the retired as they are cut off from participating in the most important interests and activities of society. Rowe (1983) has also examined the inadequacies of acceptance of self in retirement.

\section{Gender differences amongst NRP. VRP and WP on self-esteem}

Table 17: Means, standard deviation (SD), 'f value and level of significance of normally retired population (NRP), voluntarily retired population (VRP) and working population (WP)

\begin{tabular}{|c|c|c|c|c|c|}
\hline Groups & Sex ratio & & Mean XSD & - f & Significance of "'f \\
\hline \multirow[t]{2}{*}{ NRP } & $M=15$ & 21.06 & $34.54 \mid 11.31$ & -3.33 & $\mathrm{p}<0.003 *$ \\
\hline & $\mathrm{F}=11$ & & \begin{tabular}{l|l}
9.27 \\
\end{tabular} & & \\
\hline \multirow[t]{2}{*}{ VRP } & $M=15$ & 24.63 & 26.3312 .24 & -0.35 & $\mathrm{p}<0.73$ \\
\hline & $\mathrm{F}=11$ & & \begin{tabular}{l|l} 
& 12.47
\end{tabular} & & \\
\hline \multirow[t]{2}{*}{ WP } & $\mathrm{M}=16 \mathrm{~F}=8$ & 20.87 & \begin{tabular}{l|l|}
19.25 & 11.51 \\
\end{tabular} & 0.41 & $\mathrm{p}<0.69$ \\
\hline & & & \begin{tabular}{l|l}
7.88 \\
\end{tabular} & & \\
\hline
\end{tabular}

As seen in table 17, in index of self esteem significant differences were noted between men and women in NRP (' $t$ ' $=-3.33, p<0.003$ ). This showed that women had lower self-esteem than men did in NRP, but no significant gender differences were noted in VRP and WP

('t'=-0.35, p<0.73 and' t' $=0.41, \mathrm{p}<0.69)$.

This may be attributable to the fact that women who retire normally feel that there is no scope for them to be reemployed in future which brings down there feeling of self esteem. Interestingly VRP and WP did not show significant gender differences. This could be because women in VRP still have hope and scope to be reemployed which helps them to restore their self-esteem. However Irizarry (1985) in his study found that retirement did not affect the self esteem of women as they do not have to play the bread winner role like men and thus felt a more positive attitude towards retirement. Streib and Schneider (1971) suggested that women are less favorable to retirement than men. Findings of this study clearly highlight that normal retirement has negative impact on women as compared to men.

\section{Summary}

Retirement is a time when health and mental problems will surface, while economic conditions are inadequate. As retirement approaches, it becomes a bane, as there is nothing worthwhile to achieve. On the contrary people, who have set a progressive series of goals, make post retirement more meaningful. Thus one should prepare for retirement by setting up new goals in the form of vocations that can be pursued later.

The aim of the present study was to explore the impact of retirement (normal and voluntary retirement) by comparing it with working population (after 60 years of age) in the areas of adjustment (i.e. home, health, emotional life, social life and self) self esteem, life satisfaction, psychiatric morbidity (mood) and gender differences in the areas mentioned above.

For the above study three groups were taken and evaluated on various self rating questionnaires. The details of the experimental design, description of the sample, tools and instruments used and procedure are discussed in chapter 3. The data was analyzed by applying inferential statistics (ANOVA and' t' test).

For studying the relation of normally retired population, voluntary retired population and working population with adjustment, self esteem, mood and life satisfaction ANOVA was applied and for studying gender differences in the three groups with relation to the areas mentioned above T test was performed.

The research findings included the comparison of different groups in the areas discussed above. It showed that retired population and especially voluntary retire population experienced poorer adjustment in 
relation to health, emotional life, self and home. Retired population were also more depressed and showed downhill trends in having lower self esteem if compared with the working population.

None of the groups showed any differences in life satisfaction. The findings also included comparing men and women of the three populations. Women and especially who had taken voluntary retirement showed poorer adjustment in areas of health emotional life and home than men. Having thrown light on these factors, more extensive research is needed to identify the psychological disturbances in this population that are capable of leading a meaningful and productive life.

\section{Conclusion}

Elderly population commonly faces a lot of problems in various aspects of their lives, such as in occupational, interpersonal and social lives. This is attributed to various natural changes in old age as well as changes due to urbanization and modernization. Retirement is one such area that has an enduring impact on the elderly population and their life style. In this study following conclusions were drawn.

\section{In the area of adjustment:}

- Voluntary retired population reported more health-related difficulties as compared to normally retired population and working population.

- Both the retired groups (i.e. normally retired and voluntarily retired) had difficulty in adjusting towards emotional life as compared to working population.

- In the area of self, it was the working group who showed better adjustment as compared to both the retired groups.

- Working group showed significantly better family relations as compared to both the retired groups.

- Though there were no significant differences in the three groups with respect to social life, working population seemed to be having favourable trends towards a better social life.

\section{In the area of life satisfaction}

The three groups did not differ from each other. All the groups perceived life satisfaction to an average level.

\section{In the area of mood disturbances}

On mood disturbances both the retired groups (i.e. normally retired and voluntarily retired) were seen to be significantly depressed as compared to the working population.

\section{In the area of self-esteem}

Both voluntary retired population and normally retired population showed significantly lower self-esteem as compared to the Working population.

\section{MINI}

MINI scale was assessed in the VRS, NRP and WP in both genders. No major neuropsychiatric problem could be diagnosed in the study population.

\section{In gender differences}

- Women of normally retired population reported lower self-esteem as compared to men. There were no significant gender differences seen in voluntarily retired and working population.

- In the area of adjustment, women of voluntary retired population had more health problems, poor family relations (home) and difficulty in adjustment towards emotional well being as compared to men of the same population. No gender differences were noted in normally retired population and working population. Also no gender differences were seen in the area of social life and self.

- In the area of life satisfaction and mood disturbances there were no gender differences.

\section{Clinical Implications}

- Society should be made sensitive to understand the needs of retired people, and skills should be cultivated. Some public places like parks and recreation facilities especially for elderly should be established.

- Besides jobs, leisure developing skills, which can also be vocational, should be honed.

- Counselling or retirement planning and entrepreneurs skills, should be reinforced

- Since Voluntary retired population was most vulnerable, mental health professionals should plan psychosocial intervention techniques to restore mental health for retired population. Identification of depression and other mental disorders seems to be the need of the hour.

- If needed, family therapy should be done to prepare families to accept retirees. 
- Women of voluntary retired population showed poor adjustment in relation to health, emotional life and home, probably because being career women they could not deal with the sudden change in employment status, therefore suggesting that better coping skills need to be taught to this population of women.

\section{Limitations}

- Population of lower middle class was not taken as part of the research.

- Variables like socio-economic status, living condition, attitude towards retirement and personality were not analyzed (included in the study).

- Only an English or Tamil speaking population was selected which has narrowed the scope of the study because the unskilled worker and labourer categories were left out.

- Conclusion of the study cannot be generalized to a larger population, as the sample was relatively small.

\section{Acknowledgements}

I thank Prof. V. Kanagasabai, M. D., Dean, Madras Medical College for permitting me to conduct this study. I thank Professor Dr. R. Jeyaprakash, M.D., D.P.M., Director, Institute of Mental Health, Chennai for his encouragement, help and guidance.

I thank Professor Dr. V.S. Krishnan, M.D., D.P.M., Deputy Superintendent, Institute of Mental Health for his encouragement and valuable suggestions.

I thank Professor and my Guide Dr. A. Shanmugaiah, M.D., Institute of Mental Health, for his valuable guidance and immense help.

My special thanks to Dr. M. Malaiappan, M.D., and Dr. Alexander Gnanadurai, M.D., Associate Professors, Institute of Mental Health for their guidance and suggestions.

My sincere thanks are due to all the Professors and Assistant Professors of Institute of Mental Health for their encouragement and frequent inputs.

I finally acknowledge and thank all my colleagues and the participants of this study for their kind cooperation

[1]. Agarwal, K (1998): Retirement and Work- an India case-study of Male senior Citizens in an urban setting. International Sociological Association (1998).

[2]. Ahuja, N (1995): Geriatric psychiatry: In Textbook of Postgraduate Psychiatry (p.899). Jaypee Publications, Delhi, 1990

[3]. Aldcroft, J. (1964): Cited in N. Jani Study of NTC mill workers-Ahmedabad, Project report (p 10) 2000.

[4]. Aldrich, C. and Lipman, R (1976): Cited in G. Menachery Retirement: A new social phenomenon.In Retirement in India: A Psychosocial Study (p 16), Vianney publications, AP 1987.

[5]. Anant, S (1967) and Bromley, DB. (1977): Cited in G. Menachery Review of studies on retirement. In Retirement in India: a Psychosocial study (p 251) Vianney publication, AP 1987.

[6]. Anantharaman, R.N. (1980): Cited in G. Menachery Retirement: A new social phenomenon.In Retirement in India: A Psychosocial Study (p 26), Vianney publications, AP 1987.

[7]. Atchley, R.C. (1976). The Sociology of Retirement (pp. 133 - 170) Cambridge Masachusetts Schenkman Publishing Co., Inc.

[8]. Back, K, Guptill, C (1966): Retirement and Self-Ratings. In I Simpson and J. McKinney (eds.), Social aspects of ageing. Durham: Duke University press, pp. 120-129.

[9]. Bandura, A (1977): Cited in Lynette Rentoul, Psychosoical approaches to ageing and mental health. In Norman and Redfern (Eds.) Mental Health Care For Elderly People. (p24) Livingstone publication, Pearson professional Ltd, 1997.

[10]. Belgrave, LS (1987): Gender and race difference in effects of health and pension on retirement before 60 Compr. Gerontol (B) 1987 Dec; 1 (3): 109-17.

[11]. Bernard, Land Weir, D (1992): Cited in G.S: Nandhini et al, Adjustment depression and sense of well being among men and women senior citizens. Journal of Psychological Researches 40 (1-2) Jan - May 1996, p. 1-5.

[12]. Bhatia, H.S. ed. (1983): Ageing and Society: A Sociological Study of Retired Public Servants (p 42, 55, 60,145,160, 164) Arya publication, Delhi.

[13]. Birren, J.E. (1959). Cited in P.K.Dhillon Introduction. In Psycholsocial Aspects of Ageing in India (p 31). New Delhi .Concept publishing Co. 1992 .

[14]. Bose, A (1982): Introduction cited in S. Mishra (Ed) Problem and Social adjustment in old age (p 14), Gian Publishing House New Delhi. 1989.

[15]. Brocklehurst, J.C. and Allen, S.C. (1987): Social services: Geriatric Medicine for students $3^{\text {rd }}$ Ed (p 38-40) Longman Singapore publishers Ltd.

[16]. Chowdhary, P.D. (1981): Cited in S. Mishra, Behavioural factors and adjustment. In Problems and Social Adjustment in Old Age (p 138, 179). Gian publishing House, N. Delhi 1989.

[17]. Chown, S. (1970): Cited in G. Menachery Retirement : A new social phenomenon in Retirement in India : A Psychosocial Study (p 31), Vianney publications, AP 1987.

[18]. Clark, M and Anderson, B (1967): Culture and Ageing. Springfield, Illinois: Charles Thomas.

[19]. Cottrell, F (1969) Cited in R.C. Atchley Adjustment to Retirement. In The Sociology of Retirement (p109) Cambridge Massachusetts, Schenkman publishing Co: 1976.

[20]. Cox, H. (1984). Cited in P.K. Dhillon, Retirement and ageing, Psychosocial aspects of ageing in India (pp183) New Delhi. Concept Publishing Co. 1992.

[21]. Cumming, E (1964): New Thoughts on the Theory of Disengagement. In Robert Kastenbaum (ed.), New Thoughts on Old Age. New York: Springer.

[22]. Dhillon, P.K. (1992): An introduction to gerontology in Psychosocial aspects of aoino in India (pp 37-41) New Delhi, Concept Publishing Co. 
[23]. Dhillon, P.K. and Milbander, S (1992): Anxiety among retired and working class I officers: A comparative study. Psychosocial aspects of ageing in India (P185.186) New Delhi: Concept Publishing Co.

[24]. Dillard, J (1982): Cited in G. Menachery Plan of study. In Retirement in India : A Psychosocial Study (p 65), Vianney publications, AP 1987.

[25]. Donahue W., Orbach, H. et al (1960): Cited in R.C. Atchley, Background and Evolution of Retirement. In the Sociology of Retirement. (p10), Cambridge Massachusetts, Schenkman Publishing Co. 1976.

[26]. Dumazedier, J. (1982): Cited in H.S. Bhatia Individual factors in ageing and adjustment. In Ageing and Society: A Sociological Study of Retired Public Servants (p151) Arya publication, Delhi.

[27]. Edwards, R (1983): Cited in G. Menachery Life Positions and Self-Concept of retired. In Retirement in India (p 104, 106). Vianney publications, A.P. 1987

[28]. Ellison, DL (1968): Cited in R.C. Atchley Consequences of Retirement. In

[29]. The Sociology of Retirement (p88) Cambridge Massachusetts, Schenkman publishing Co. 1976.

[30]. Erikson, E (1956): Cited in Lynette Rentoul, Development problems in later life. In Norman and Redfern (Eds.) Mental Health Care For Elderly People. (p70) Livingstone publication, Pearson Professional Ltd1997

[31]. Fields, M. (1971): Ageing with honour and dignity, (p.80) Charles Thomas.

[32]. Friedman, E and Havighurst, R.J. (1954): The Meaning of Work and Retirement. Chicago: University of Chicago Press.

[33]. Goode, W.J. (1977): Cited in G. Menachery Retirement: A new social phenomenon.ln Retirement in India: A Psychosocial Study (p 22), Vianney publications, AP 1987.

[34]. Gormly, A (1989): Late adulthood : Family life, social relations and retirement.In Lifespan Human Development (p 554) Holt, Rinehart and Winston Inc. 1989

[35]. Guha, BP (1997): Voluntary Retirement: Problems and Prospects of Rehabilitation (p 87, 99,167,170) Shri Ram Centre for Industrial relations and Human Resources, New Delhi (1997).

[36]. Gupte, V., Nandkumar et al (1994): Introduction in Voluntary Retirement Schemes and workers response. Friedrich - EbertStiftung (India office). Publishers.

[37]. Hamlin, R.M. (1967): Cited in G. Menachery, Retirement: A new social phenomenon.In Retirement in India (p30). Vianney publications, A.P. 1987.

[38]. Haravan, T (1995): Changing images of ageing and the social construction of the life course, In Mike and Wernick, Andrews (Eds) Images of ageing: Cultural Representations of Later Life (pp-119-134). London: Routledge

[39]. Haynes et al (1978): Cited in the Meaning of Work, the Impact of Retirement. In M. Jeffery growing old in the 20 ${ }^{\text {th }}$ Century (p-119). Billing and Sons Ltd. Worcester 1991. .

[40]. Henry, WE. (1961): Growing Old: The process of disengagement. New York: Basic Books.

[41]. Heyman, D.K. and Jeffers, F.C. (1968): Wives and Retirement: A Pilot Study. Journal of Gerontology. 23:488-496

[42]. Hbchschild, A.R. (1973): Behavioural factors and Adjustment cited in S. Mishra (Ed.) Problem and Social adjustment in old age (p1761 Gian Publishing House New Delhi. 1989.

[43]. Hollis, LA (1998): Sex compansious in Life satisfaction and psychosocial adjustment scores with an older adult sample. In Journal of women and ageing 1998; 10 (3): 59-77.

[44]. Honig, M. (1998): Married women's retirement expectations: do pensions and social security matter? The American Economic Review 88 (2) May 1998 P 202-296

[45]. Hurlock, E (1976): Cited in G.S. Nandhini et al, Adjustment depression and sense of well being among men and women senior citizens. Journal of Psychological Researches 40 (1-2) Jan -"May 1996, p. 1-5.

[46]. Irizarry, A (1985): Gender differences in preretirement attitude and activities in a Puerto Riean Sample. In P. R. Health and Science Journal (1985) Dec; 4 (30): p. 137-44

[47]. Jamuna, D (1984): Cited in P.K. Dhillon Anxiety among retired and working class I officers: A comparative study. Psychosocial aspects of ageing in India (p 170) Concept Publishing Co. New Delhi (1992).

[48]. Jamuna, D (1989): In psychological perspectives of problems of rural elderly women. In R. Pati and Jena (Eds): Aged in India: Sociodemogrpahic Dimensions (p 200,204) New Delhi, Ashish Publications, (1989).

[49]. Jani, N. (2000): Study of NTC mill workers - Ahmedabad, Project Report (p 8) 2000.

[50]. Jaslow, P (1976): Employment, Retirement and Morale among older women, Journal of Gerontology 37, p. $287-293$.

[51]. Jeffery, M. (1991): Growing old in the $20^{\text {th }}$ century. (p24) Billings and Sons Ltd. Worcester.

[52]. Jung C, (1972): Cited in Lynette Rentoul, Psychosoical approaches to ageing and mental health. In Norman and Redfern (Eds.) Mental Health Care For Elderly People. (p24) Livingstone publication, Pearson professional Ltd1997.

[53]. Kerchhoff, AC (1966): Family Patterns and Morale in Retirement. In I Simpson and J. McKinney (eds.), Social aspects of ageing. Durham: Duke university press, pp. 173-194

[54]. Kogan, L, Wallach, (1961): Attitude towards old people in an older sample. Journal of Abnormal Psychology. Feb. (2) 8 (p.54-56).

[55]. Langford, M (1962): Cited in R.C. Atchley Consequences of Retirement. In The Sociology of Retirement (p88) Cambridge Massachusetts, Schenkman publishing Co. 1976.

[56]. Laslett, P. (1989): Cited in Lynette Rentoul, Psychosoical approaches to ageing and mental health in Norman and Redfern (Eds.) Mental Health Care for Elderly People. (p34) Livingstone publication, Pearson professional Ltd1997.

[57]. Lawton, G (1951): Behavioural factors and Adjustment cited in S. Mishra (Ed.) Problem and Social adjustment in old age (P192.196). Gian Publishing House New Delhi. 1989.

[58]. Loether, H.J. (1967): Cited in the. Meaning of Work, the Impact of Retirement. In M. Jeffery growing old in the 20 ${ }^{\text {th }}$ Century (p119). Billing and Sons Ltd. Worcester 1991.

[59]. Lowenthal, M (1964): Social Isolation and Mental Illness in Old Age. American Sociological Review. 29:54-70.

[60]. Maddox, G.L. (1965): Cited in G. Menachery Retirement: A new social phenomenon.ln Retirement in India: A Psychosocial Study (p 28), Vianney publications, AP 1987.

[61]. Malik, P.L. (1980): Cited in G. Menachery, Retirement: A new social phenomenon.ln Retirement in India (p30). Vianney publications, A.P. 1987.

[62]. Makides KS, Cooper CL (1989): Cited in Lynette Rentoul, Psychosoical approaches to ageing and mental health. In Norman and Redfern (Eds.) Mental Health Care For Elderly People. (p34) Livingstone publication, Pearson professional Ltd1997.

[63]. Me Michael and Tyroler (1977): Cited in G. Menachery Retirement: A new social phenomenon.ln Retirement in India: A Psychosocial Study (p 36), Vianney publications, AP 1987.

[64]. McGoldrick, A.E. (1989): Cited in Lynette Rentoul, Psychosoical approaches to ageing and mental health. In Norman and Redfern (Eds.) Mental Health Care For Elderly People. (p34) Livingstone publication, Pearson professional Ltd1997.

[65]. Menachery, G. (1987): Plan of study. In Retirement in India: A Psychosocial Study (p 91), Vianney publications, AP 1987. 
[66]. Mercier, J (1996): Sense of Control among Religious Women. Journal of Religious Gerontology: 1996, 9, 4, 7-26.

[67]. Merrill, G. (1976): Retirement depression (1976): Md State Med. Journal 1976; 25 (3): (p.47-50).

[68]. Midanik, LT (1995): The effect of retirement on mental health and health

[69]. Behaviours: the Kaiser Permanente retirement study. In Journal of Gerontology and Psychology and Social Science. 1995 Jan ; 5 (1) :p. 559-561

[70]. Miller, S (1965): Cited in R.C. Atchley Adjustment to Retirement. In The Sociology of Retirement (p112) Cambridge Massachusetts, Schenkman publishing Co. 1976.

[71]. Mills, C, (1956): Cited in R.C. Atchley, Background and Evolution of Retirements the Sociology of Retirement (p15) Cambridge Massachusetts. Schenkman Publishing Co. 1976.

[72]. Mishra, S (1989): Situational factors and Adjustment. In problem and social Adjustment in old age (p 71) Gian publishing House, N. Delhi.

[73]. Mohanty, S. (1989): Retired government servants and their problems of sociopsychology adjustment. In Pati and Jena (Eds.) Aoed in India (p 222) Ashish publication, New Delhi 1989.

[74]. Muttagi, P.K. (1997): The Indian situation. In Aging issues and old age care (p.50) Classical publishing company, New Delhi.

[75]. Nagar, S. (1989). Status and care of the Aged in India and Japan. In M.L. Sharma and T. M. Dak (Eds), Ageing in India: Challenge for the society (pp 187 -189), New Delhi Ajanta Publication (India).

[76]. Nandhini, S., Geeta, S (1996): Adjustment depression and sense of well being among men and women senior citizens. Journal of Psychological Researches. 40 (1-2): 1996: pp 1 - 5.

[77]. Nadelson, T (1969): A Survey of the Literature on the Adjustment of the Aged to Retirement. Journal of Geriatric Psychiatry. 3:320.

[78]. Ostberg, H. (1994): Occupational retirement in women due to age. Health aspects. Scand J Soc Med 19 Jun; 22(2): 90-6.

[79]. Paintal, H.K. (1977): Cited in G. Menachery Retirement: A new social phenomenon.In Retirement in India: A Psychosocial Study (p 28), Vianney publications, AP 1987.

[80]. Palsane, M.N. (1970): in G. Menachey (Ed) Plan of study. In Retirement in India: A Psychosocial Study (p 97), Vianney publications, AP 1987.

[81]. Peck, R.C. (1968): Cited in Lynette Rentoul, Psychosoical approaches to ageing and mental health. In Norman and Redfern (Eds.) Mental Health Care For Elderly People. (p23) Livingstone publication, Pearson professional Ltd1997.

[82]. Peterson.D (1972): Cited in R.C. Atchley Consequences of Retirement.

[83]. In The Sociology of Retirement (p102) Cambridge Massachusetts, Schenkman publishing Co. 1976.

[84]. Pitt, B (1990): Mental health in retirement- Can deterioration be prevented, Journal of Social Health 1990 June; 110(3): 81-4

[85]. Quick, HE (1998): Gender employment and retirement quality: a life course approach to the differential experiences of men and women. In Journal of Occupational Health Psycho (1998) Jan;3(1); 44-64

[86]. Ramamurthi, P (1970): Problems of older people- an analysis of age trends. Psychological Studies. 15. pp 128-130.

[87]. Ramamurti, P.V. (1987): Cited in D. Jamuna Psychiatric perspectives of the problem in Pati and Jena (Eds.) Aged in India 43). Ashish publication, New Delhi 989

[88]. Ramchandran, V (1982): Geriatric Psychiatry in J. N. Vyas and N. Ahuja (Eds). * Textbook of Postgraduate Psychiatry (pp 898 899) Jaypee publications.

[89]. Ramchandran, V., Palaniappan (1983): Geriatric psychiatry in J.N. Vyas and N. Ahuja (Eds). Textbook of Postgraduate Psychiatry (p899) Jaypee publications.

[90]. Rao, V (1982): Cited in V Ramchandran Geriatric Psychiatry in Vyas and N. Ahuja (Eds). Textbook of Postgraduate Psychiatry (pp 899) Jaypee publications.

[91]. Rao, V. (1996). Depression. A psychiatric analysis of 30 cases. Indian Journal of Psychiatry. Vol. 8 (2): pp. 143 -151.

[92]. Riley, M.W. Foner, A.E. (1965): Ageing and Society: Volume I, An inventory of research findings. New York: Russell Sage Foundations.

[93]. Rollins BC, Feldman H (1970): Cited in R.C. Atchley Consequences of Retirement. In The Sociology of Retirement (p84) Cambridge Massachusetts, Schenkman publishing Co. 1976.

[94]. Rosow, I (1963): Introduction cited in S. Mishra (Ed) Problem and Social adjustment in Old Age (p 12) Gian Publishing House New Delhi. 1989.

[95]. Ross, A.D. (1981): Cited in H.S. Bhatia Individual factors in ageing and adjustment. In Ageing and Society, a Sociological Study of Retired Public Servants (p 102) Arya publication, Delhi 1983.

[96]. Rotter, J.B. (1966): Cited in Lynette Rentoul, Psychosoical approaches to ageing and mental health. In Norman and Redfern (Eds.) Mental Health Care For Elderly People. (p24) Livingstone publication, Pearson professional Ltd1997.

[97]. Rowe, A (1983): in G. Menachery (Ed) Plan of study in Retirement in India: A Psychosocial Study (p 93), Vianney publications, AP 1987.

[98]. Russell, W (1979): Special features of the sample cited in S. Mishra (Ed). Problem and Social adjustment in old age (p61), Gian Publishing House New Delhi 1989.

[99]. Salem (1976): Cited in the Meaning of Work, the Impact of Retirement.

[100]. In M. Jeffery growing old in the $20^{\text {th }}$ Century (p-119). Billing and Sons Ltd. Worcester 1991.

[101]. Sethi, B.B. (1982): In G. Menachery in Plan of study in Retirement in India: A Psychosocial Study (p 104), Vianney publications, AP 1987.

[102]. Shanas, E. et al. (1972): Old people in three industrial societies, New York: Atherton Press.

[103]. Sharma, K. L and Jain, U. C. (1987): Attitudinal factors and Adjustment cited in S. Mishra (Ed). Problem and Social adjustment in old 306(01131, Gian Publishing House New Delhi. 1989.

[104]. 1OO.Simpson, I and Back, K. (1969): Cited in R.C. Atchley Consequences of Retirement. In The Sociology of Retirement (p94) Cambridge

[105]. Massachusetts, Schenkman publishing Co. 1976. 101. Simpson, I.H. et al (1966): Cited in P.K. Dhillon, Perceived social support and effect of life events. In Psychosocial aspects of ageing in India (P 196) New Delhi: Concept Publishing Co. 102. Singh, B.S. (1982): Cited in Lynette Rentoul, Developmental problems in later life. In Norman and Redfern (Eds.) Mental Health Care For Elderly People. (p83) Livingstone publication, Pearson professional Ltd1997.

[106]. Singh, J. et al (1983): Cited in anxiety among retired and working Class I officers in PK Dhillon (Ed) Psychosocial Aspects of Aging in India (p 192) Concept Publishing Co. New Delhi <1992)

[107]. Singh, J.G. and Dawra, V. (1983): Study of personality of aged in India. In Dr. Joseph (Ed) Aged in India- Problems and Personality, (p91), Chugh Publication, Allahabad, 1991. 
[108]. Sinha, P. (1994). Cited in M.K. Institute and Friedrich Ebert Stiftung-An overview. In Voluntary Retirement Scheme and Workers Response (p 2) India office; New Concept Information System New Delhi 1994

[109]. Sinick, D (1977) In G. Menachery Future of retirement in India in retirement in India. In Retirement in India: A Psychosocial study (p140) Vianney Publications, AP (1987).

[110]. Special staff on aging, US Dept of Health, Education and Welfare, the Nation and its older people: A report Jan $9^{\text {th }},(1961)$ pg -117.

[111]. Streib, G and Schneider, G (1972): Cited in R.C. Atchley Consequences of Retirement. In The Sociology of Retirement (p89, 93) Cambridge Massachusetts, Schenkman publishing Co. 1976.

[112]. Streib, G and Thomson, W (1957) Situational factors and Adjustment in Mishra (Ed). Problem and Social adjustment in old age (p87), Gian Publishing House New Delhi. 1989.

[113]. St.reib, GF and Schneider, CJ (1971): Cited in late adulthood: Family life, social relationship and retirement. In A. V. Gormly and D. Brodzinsky (Eds.) Lifespan Human Development (p 554) Holt, Rinehart and Winston Inc1989. m.Streib, GF. And Scheinder, CJ. (1971): Cited in Anxiety among retired and working class I officers in P.K. Dhilloh (Ed) Psychosocial aspects of ageing in India 184) New Delhi, concept publishing Co 1992.

[114]. Sugisawa, A et al (1997). Effect of retirement on mental health and social well being among elderly Japanese. Japanese Journal of Public Health 44 (2): 123-30, Feb 1997.

[115]. Thompson, W, Streib G et al (1960): Cited in RC Atchley Adjustment to retirement, in The Sociology of Retirement (pp.90-122) Cambridge, Massachusetts Schenkman Publishing co. (1976)

[116]. Thomson, W (1958): Introduction cited in S. Mishra (Ed) Problem and Social adjustment in old age (p 12), Gian Publishing House New Delhi, 1989.

[117]. US. Senate Special committee on ageing (1986). Ageing America: Trends and projections. Washington D.C., US Govt. printing office. Walker, Alan (1985): The social division of early retirement. In Margot Jefferys (Ed) Growing Old in the $20^{\text {th }}$ century (pg.73) Billing and Sons Ltd. Worcestor. (1991)

[118]. Yamashita K, Kobayashi \$ et al (1993): Feelings of Well-being and Depression in relation to Social activity in Normal Elderly people in Nippon. Ronen Igakkar Zasshi (1993) Aug 30 (8): 693-7 